\title{
Semiotic Shortcuts: The Graphical Abstract Strategies of Engineering Students
}

\begin{abstract}
Graphical abstracts are representative of the rising promotionalism, interdisciplinarity and changing researcher roles in the current dissemination of science and technology. Their design, moreover, amalgamates a number of transdisciplinary skills much valued in higher education, such as critical and lateral thinking, and cultural and audience awareness. In this study, I investigate a corpus of 56 samples of graphical abstracts devised by my aeronautical engineering students, to find out the 'semiotic shortcuts' or encoding strategies they deploy, without any previous instruction, to pack information and translate the verbal into the visual. Findings suggest that their 'natural digital-native graphicacy' is conservative as to the medium, format and type of representation, but versatile regarding particular meanings, although not always unambiguous or register-appropriate. Consequently, I claim the convenience of including graphicacy/visual literacy and some basic training on graphical abstract design in the English for Specific Purposes and the disciplinary English-medium curriculum.
\end{abstract}

\section{Keywords}

Graphical abstracts, engineering contexts, graphicacy/visual literacy, semiotic encodings, visual metadiscourse

\section{Why graphicacy in higher education?}

There are several sound reasons to teach visual literacy in university contexts, and in particular applied to the graphical abstract genre: science and technology students will sooner or later have to cope with the consequences of globalisation (i.e. increased promotionalism, abridgement of information, mixed audiences) and with the visuality inherent in their fields when communicating academically or professionally with both expert and lay people. To this rationale adds the Bologna Process, whose guidelines are being implemented within the European Higher Education Area (henceforth EHEA) and aim at encouraging critical and proficient use of information and transversal competencies ${ }^{1}$ such as creativity, IT expertise, or intercultural awareness, closely connected with visual expression. Let us examine each of these three arguments in turn.

First and foremost, the globalised and interdisciplinary world of today, where science and technology have inevitably become commodities (Swales 2004, Gross/Chesley 2012) and increasingly exhibit a promotional tone in their discourses (Bhatia 2004, Pérez-Llantada 2012), demands that researchers/scientists expand their traditional roles to adopt those of divulgators, editors, designers, art directors, performers and marketing experts. These new functions or identities have

1 Following Thornbury (2006: 38-39) and Black (2012: 150-153), I distinguish between 'competencies' and 'skills'. Competencies are the frameworks or combinations of knowledge, abilities, mindsets and behaviours needed to teach or train in a specific practical skill and that lead to successful performance. Skills are the abilities acquired through practice and training, exercised in the service of some other end and appraised in terms of how well or badly they are done.

\footnotetext{
* Carmen Sancho Guinda

Technical University of Madrid (UPM)

Department of Linguistics Applied to Science and Technology

Spain

carmen.sguinda@upm.es
} 
been noted by previous studies on emergent academic genres, such as the video essay (see, for example, Maier/Engberg 2013).

In effect, researchers from hard and soft sciences alike must nowadays select and arrange specialized information to address broader audiences (expert, mixed, lay), which often involves dealing with multimodal media and more varied communication channels: we have come to know of professors who have their research published in 'fascicles' via Amazon, film 'research trailers' to publicise their scientific projects and thus capture the attention of prospective sponsors, or 'summarise summaries' to facilitate the screening of specialised literature and comply with the requisites of certain academic events. This extreme encapsulation of contents is frequent in massively-attended conferences which include 50-word abstracts in their programmes, and in fast-evolving technologies whose highly-cited publications insert teaser abstracts, normally under 30 words (Sancho Guinda 2014a, 2015), right away in their tables of contents, as is the case of the Proceedings of the IEEE (Institute of Electrical and Electronics Engineers). If the verbal abstract has traditionally been perceived as much advertising as it is informative (Hyland 2004), its graphical version enhances even more the promotional component because of the immediacy and impact of visuals and the documented inclusion of corporative logos (Sancho Guinda 2015) to disclose sponsorship.

A second powerful reason for tackling visual literacy and graphical abstracts (hereinafter GAs) in tertiary education lies in the very history of science. Certainly, scientific iconography has existed, with its mimetic limitations, since time immemorial, and many a scholar has stressed its importance, not only as a tool for reproducing nature and popularizing complex reasoning to 'show rather than tell', but also to generate knowledge (Tufte 1983, Lynch 2006, Pauwels 2006b, Trumbo 2006, Kress 2010). Pauwels (2006a: viii), for one, holds that visual representations "are an essential part of scientific discourse". In this line, Latour/Woolgar (1979: 237) asserted that "whatever scientists can know of their objects is a consequence of the way they represent them", and longer ago Tufte (1983) had posited that graphics are an integral step in the analysis of data and can shape an argument as much as be shaped by it, and that they nurture an aesthetic sensibility necessary to think clearly and well. In support of this view, according to Cambrosio et al. (2006), visual renderings create contextual frameworks with which to express and test hypotheses. This overall attitude in favour of an explicit instruction on the visual encoding and interpretation of scientific content is embodied in Kress' (2010: 27) recent observation that "representation makers are knowledge makers", which may bring along issues of identity and power, and has been claimed for by a number of scholars under the names of visual or graphic literacy (Dondis 1973, Messaris 1994, Swales/Feak 1994, Myers 2003, Trumbo 2006, Sancho Guinda 2011, 2012a, 2012b, 2014b, 2015), graphicacy (Balchin/Coleman 1966, Poracsky/Young/Patton 1999) and visual grammar or grammar of visual design (Kress/van Leeuwen 1996).

As for the EHEA trends, the European Reference Framework (European Parliament \& Council 2006) defines in its Annex a series of key transversal (i.e. transferable across disciplines and tasks) competences to be pursued for life-long learning, among which are the critical use of information and the creative and culture-aware transmission and expression of ideas and experiences. To bring this pedagogical enterprise to fruition, I advocate an explicit visual literacy or graphicacy instruction in university settings through the GA genre. My interest is to help learners develop academically richer transductions to raise their genre literacy and help them construct and represent specific knowledge more efficiently. Transduction (Kress 2010: 125) is the translation of meaning from one mode to another, for example, from speech to image or vice versa. I will focus upon the strategic rankshifts (Fredlund et al. 2014) or 'semiotic shortcuts' devised by novice GA designers (in this case my senior engineering students) to pack knowledge with the affordances available (verbal text, diagrams, drawings, graphs, photographs and film). Alongside with this goal I aim at activating students' and researchers' transferable skills and honing their intercultural awareness and sensitivity towards audiences. 
Before going on to inform about the provenance and characteristics of my data and to analyse them so as to trace patterns, find gaps and propose solutions, I will first comment on the visual learning tradition in my everyday teaching context, the School of Aeronautical and Aerospace Engineering (ETSIAE for short, its acronym in Spanish: Escuela Técnica Superior de Ingeniería Aeronáutica y del Espacio) at the Technical University of Madrid, and examine more in detail the challenges posed by GAs in general.

\subsection{The visual tradition in STEM environments}

Learning, argue Kress et al. (2001: 1, 27, 29), is "a dynamic process of sign making" that can no longer be treated as "dependent on language centrally, or even dominantly". This is especially true in STEM circles (i.e. the acronym stands for science, technology, engineering and mathematics), in which students and professionals rarely verbalise to their peers the graphic information they so readily apprehend and use as part of the restrained persuasion (Sales 2006) typical of their reasoning style (i.e. non-argumentative and factual).

At the ETSIAE it is common that the graphic component of the support materials for lectures (e.g. class notes and laboratory booklets), compiled and/or written by teachers and printed and bound by the reprography services, amounts to $80 \%$ of the information they contain, sometimes with hardly any legend or minimal verbalisation. Obviously, students are expected to grasp technical contents visually, but this assumed requirement does not ensure that they are able to create competent visuals, attuned to the characteristics of their audience. Myers (2003) remarks that graphic decodification is learnt intuitively and autonomously, without any instruction, during the early years of secondary education, and that this learning autonomy does not apply to the obverse, that is, to the verbalization of visuals or to their construction adjusted to the background of the addressee.

Graphicacy is a holistic construct that includes three major abilities: visual thinking, visual learning and visual communication (Trumbo 2006). They respectively consist in the organization of thought into imagistic schemata and recourse to shape, line, colour and composition to make them meaningful (i.e. the use of elements key to Kress and van Leeuwen's visual grammar), the interpretation of images created by others, and the creation and transmission of symbols to convey ideas, because science is conceived of by some scholars (e.g. Latour 1990) as a symbolic enterprise. Hence graphicacy calls for the building and acquisition of intercultural repertoires to encode and decode information. By means of graphicacy, in addition, learning is enhanced (Dwyer 1978) through the exercise of higher order thinking skills: comparison and contrast, exemplification, clarification of ideas, summarizing, prediction of effects regarding comprehensibility, memorability, accuracy and credibility, and decision-making depending on all the former. These thinking abilities have a bearing on the choice of visual representation, whether 'ready-mades', 'cultivations', or 'abstractions' (Lynch 2006). The first of them is what we may understand as a tableau vivant, a graphic ensemble of natural elements (e.g. geological exposures of particularly well-aligned strata). The second comprises different methods of enframing (e.g. graphic embeddings, labelling, gridding, etc.) to categorize and delimit boundaries. Last, the third is an extreme simplification (e.g. through symbols, indices, graphic points, etc.) to facilitate comparison, calculation, standardization, circulation and theoretical analysis, and be universally legible.

Visualisation, nevertheless, entails a certain degree of difficulty because it neither just mediates between the real object and the human perceiver, nor parallels the linear logic of the verbal text, a trait underlined by Machin (2007). Visuals, in contrast, are holistic, amalgamated, synthetic, dynamic and open (Barry 1997), due to which some scholars (Dondis 1973, Messaris 1994, 1998) have concluded that they can, at the most, simply function as valuable complements to verbal language. Corroborating this intersubjective (Lynch 2006) qualification of visuals, GAs have not, as yet, appeared without their verbal counterparts in academic journals. 


\subsection{The exercise of graphicacy at the ETSIAE}

To find out about the type and level of graphicacy experience stimulated at the ETSIAE, and with it my students' visual literacy, I conducted semi-structured interviews (see Appendix) with a volunteer cohort of 18 lecturers from different departments (Applied Mathematics, Physics, Materials Science, Air Transportation and Aerospace Vehicles). I wanted to know: 1) what was the relationship between the verbal text and the graphics facilitated by these teachers to assist learning in class notes, laboratory booklets and during lectures, and 2) what type of tasks involving visuals were assigned to students. The first inquiry may clue us as to the type of visual functions students are mostly exposed to and that might bear an influence on their strategies for designing GAs. The second one, which might also be influential on GA design, reveals what cognitive skills involving visuals are developed throughout the degree years. Together, these two inquiries give an idea of the 'background of visual culture' learners set out with to face visual and multimodal genres.

By visuals/graphics the teachers interviewed predominantly understood graphs, tables and schematic diagrams. The two other categories into which Gross et al. (2009) divide visuals in the $20^{\text {th }}$ century (i.e. photographs and realistic drawings) were reported to hardly be part of assignments, although teachers use them sparingly when exposing theoretical contents in their lectures. For example, in the subject of Materials Science, microscopic pictures serve to show students different degrees of corrosion, fatigue, stress, etc., and in the specialty of Airports and Air Transportation, aerial photographs of airport layouts and facilities and the flight trajectories of aircraft are often utilized. It is worthy of note that none of the interviewees had contemplated the possibility of using GAs in their lectures or as support materials.

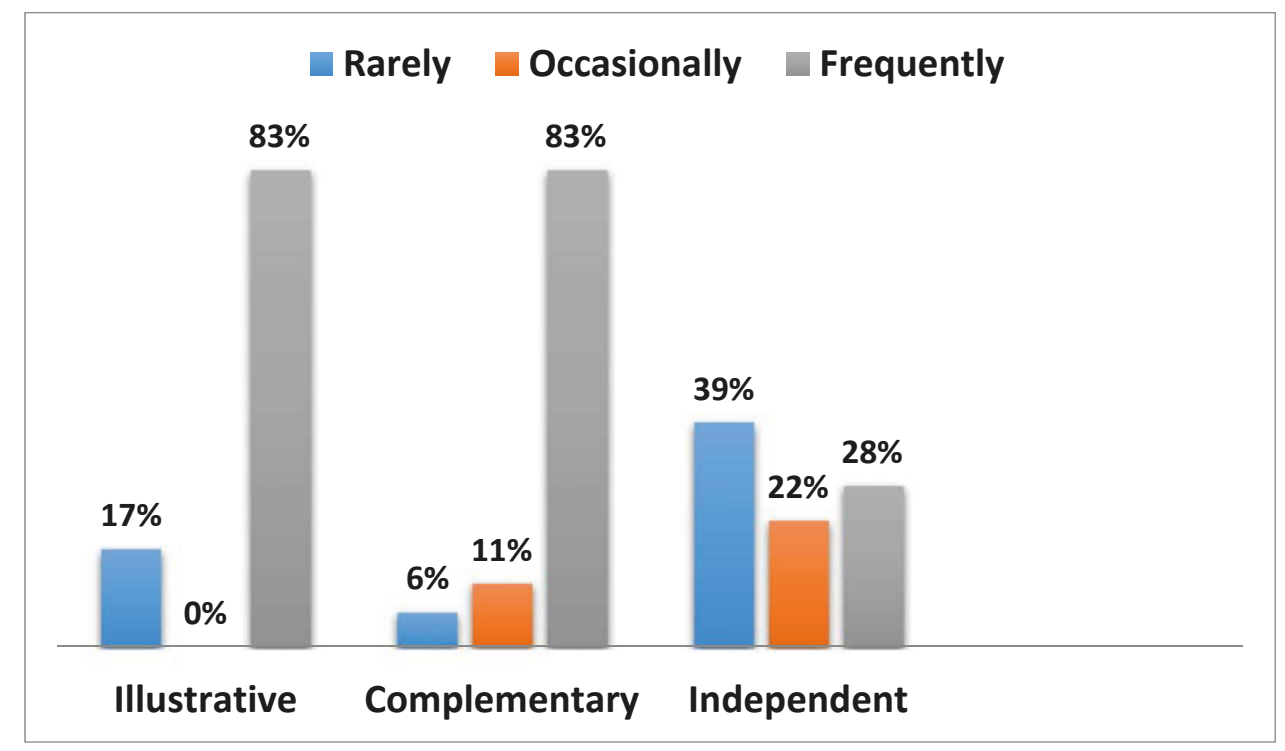

Figure 1. Informative function of the visuals facilitated by ETSIAE teachers

As observed in Figure 1, where the vertical axis represents the percentage of informants and the horizontal one the relationship between the visual and the surrounding verbal text, the visual input provided by the engineering teachers in my study is frequently intended, in the same proportion, to exemplify and complement the verbalized message. Much less widespread is the use of a visual as the sole source of information, independently of any verbal content. According to these teacher routines, we should expect students to construct GAs that mostly exemplify or complement aspects of the verbal text rather than summarise it, and to lean on language to make the visual message intelligible. 


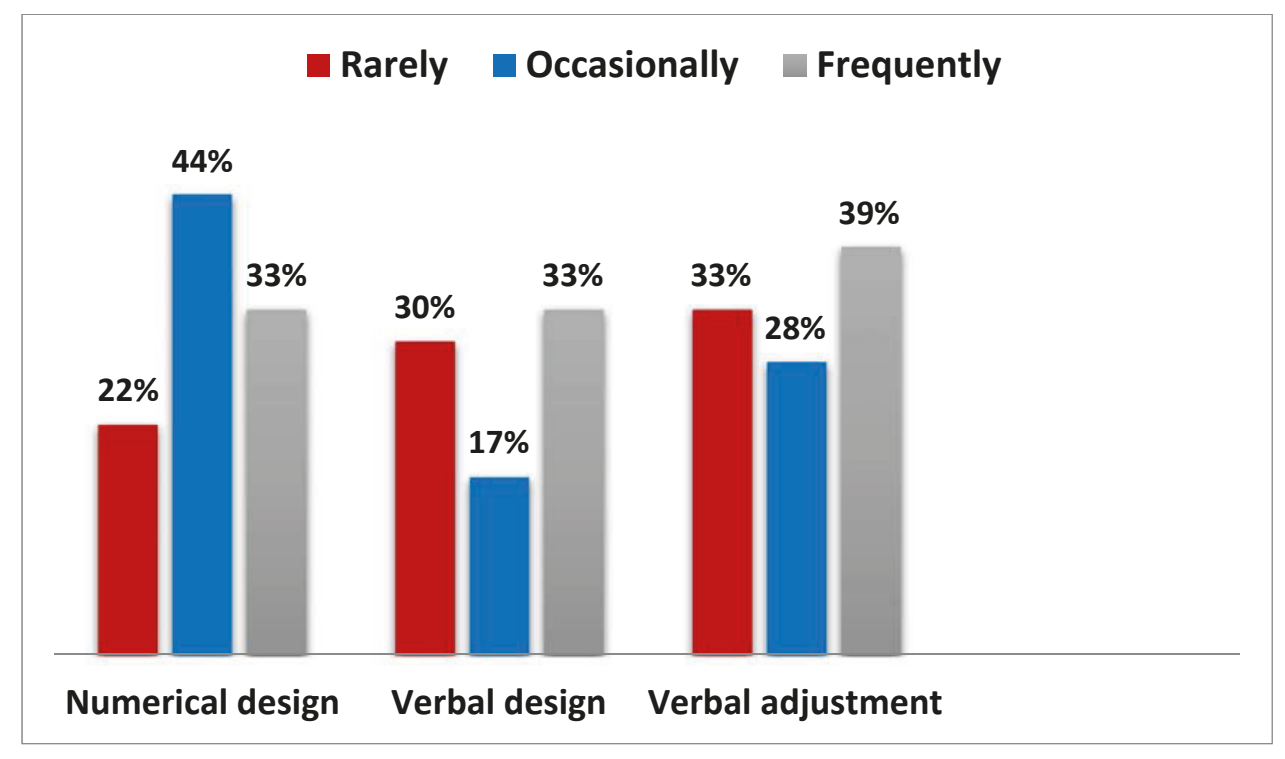

Figure 2. Type of visual task assigned to ETSIAE students

From Figure 2 we may deduce that aeronautical engineering students are accustomed to transmitting visual information to their peers and not to mixed or lay audiences. The first variable or task ('numerical design') is the creation of visuals from tabulated numerical data. The second one ('verbal design') consists in devising a visual from a verbal description or narrative, and the one labelled as 'verbal adjustment' in adapting a commentary of visual data to concrete audiences and communicative situations. This verbal adjustment of technical contents usually takes place implicitly, in the oral presentations prepared by a work team as part of their group project and which are delivered to other groups of peers in the class and to the teacher. Each presenting group becomes the 'expert in the topic' and their audience can be considered a mixed one.

Unlike in the English for Specific Purposes class, where verbal expression is the instructional focus, in the disciplinary subjects the delivery of oral presentations is not so much text- but content-centred, although of course conceptual simplification leads to an increase in glosses, analogies, clarifications and explanations. Only occasionally, however, does the need for simplification impel speakers/writers to design extra easier-to-grasp visuals ad hoc, which are most often motivated by the illegibility and/or complexity of a former version, or by a disproportionate amount of speech referring to a single slide. Additional graphic support, then, is not generally perceived as a remedy for conceptual density or messages not adjusted to the interlocutor, but rather as an attention-sustaining device. Because communication is not a priority in disciplinary subjects, and in engineering settings interactions are supposed to take place among experts, the simplification of texts through visuals is scarce and very seldom caused by a concern with the knowledge background and interests of the intended audience.

\section{Why graphical abstracts?}

The pedagogical potential of GAs is ample, owing to their currency as scientific genre and the variety of interrelated transversal competencies and skills it demands. To begin with, the intercultural awareness, critical and lateral thinking, and IT literacy favoured by the EHEA curricula converge in the design of visual codes and compositions as universal as possible, since the huge affluence of information circulating in these globalised and endemically multimodal times requires a "trans-national interconnectedness" and "semiotic mobility" (Blommaert 2005: 50, 69). This means that the transference of affordances, discourses and texts to new contexts must be ac- 
companied by a specific metadiscourse ${ }^{2}$ that informs of the preferred interpretation of the new message. Academia, for instance, is growing more international and interdisciplinary, and its expert audiences more heterogeneous. 'Multiple memberships' are becoming rife in any community of practice (Wenger 1998, 158) and new communication formats, aimed at massive audiences across disciplines and borders, have incorporated features such as multimodality, hypertextuality and interactivity to traditionally written genres like the research article. These emerging formats are fostered by computer-mediated communication and known as 'multimodal composites' (Hoffmann 2010). Time will tell whether their hypertextual and interactive features will soon reach the abstract genre, which turned visual in 2011 with Elsevier's 'The Article of the Future' project', a new prototype format tailor-made by the editorial group to broaden its scientific readership. Swales' prediction $(2014,323)$ is that by 2035 all abstracts will be graphical "if Elsevier gets its way", but they might become hypertextual and interactive too. For now, nonetheless, GAs merely retain a "symbiotic" status (Sancho Guinda 2015), acting as a paratextual gloss of their verbal version.

A fruitful group project or class activity in connection with these genre innovation issues might consist in asking students to keep a 'textual surveillance' on the evolution of the genre within their own field of interest, and report on existing variants and on whether new formats and affordances are incorporated. Class discussions over the meaning-making strategies identified in the main variants could even lead to the elaboration of a rubric for GA interpretation and of an inventory of impact journals that include GAs and the specific research areas in which they abound. Identification tasks of this sort could pave the way for productive ones involving content selection, rhetorical choices and meaning-making.

The unavoidable incompleteness and subjectivity of GAs and their logical dependence on verbal texts have caused many online impact journals to display GAs and verbal abstracts together. This fact does not prevent GAs from being, on many occasions, the first, or even the only, gateway to the article, what entices us to read on. This enticing function again fuses the aforementioned EHEA competencies, but the careful analysis of aesthetic and intercultural values becomes paramount to create attractive messages that capture the reader's attention so as to promote research widely. To conclude, like verbal abstracts, GAs involve the higher-order cognitive skill of summarising contents within a limited extension of text (but in terms of file size and number of panels), which is another argument to include the genre in disciplinary and academic or professional communication syllabi. It is infrequent that GA summaries contain the complete IMRD narrative (i.e. the introduction/method/results/discussion sequence of research actions), and a selection of verbal abstract moves (rhetorical choices) must be made according to the relevance of the move and the representation restrictions imposed by the journal.

\subsection{GAs as hybrid practices in permeable communities}

In previous work (Sancho Guinda 2015) I have pointed out the vagueness of GA guidelines in the online style sheets of those journals that admit or request this genre variant. With the exception of Cell, one of Elsevier's ${ }^{4}$ most prestigious scientific publications, the rest of journals accept as GAs key figures from the full paper or ad hoc ones, provided that they encapsulate the take-home message of the article, encourage browsing and interdisciplinary scholarship, and meet specific

2 Metadiscourse, according to Hyland (2005: 3-4), is a concept that comprises a range of discoursal features (e.g. hedges, connectives and various forms of text commentary) to align with the reader in a particular context and guide or influence his/her reception of the message. Through metadiscourse writers not only guide the reader's interpretation and achieve a more reader-friendly prose, but also convey their personality, credibility, audience-sensitivity and relationship to the content.

3 https://www.youtube.com/watch?v=1dXkmgkYuEg

$4 \mathrm{https} / /$ www.elsevier.com/authors/journal-authors/graphical-abstract 
format criteria such as shape, size, font, and type of file. Taylor and Francis online ${ }^{5}$, the other editorial giant that promotes the use of GAs and first-page previews, does not even furnish authors with directions, and its uncommented samples strongly focus on Chemistry and closely related fields. The same attitude is found in Synthetic Communications. An International Journal for Rapid Communication of Synthetic Organic Chemistry, which belongs to the same publishing group and whose GAs are restricted to the development of chemical equations. Slightly more explicit, the journals of the Federation of European Microbiological Societies (FEMS) ${ }^{7}$, advise authors to keep the GA simple by using a short legible text and discarding saturated distracting colours. They set a minimum image resolution (300dpi) and aspect ratio (4:3) for image optimisation with their click-and-expand device, and the only obligatory feature is being appealing, so that the article can be promoted via social media, newsletters and online search results. FEMS journals' GAs may be or contain any visual from the paper or not be linked to the original manuscript at all. Cell ${ }^{8}$, by contrast, rejects graphics which are already in the paper, and specifies that the newly created visual must take up a single panel and either make a point or highlight one process or procedure. It must also avoid speculation, have a clear start and end and a reading path from right to left or from top to bottom, provide labels and indications, include brief portions of verbal text but without data, and be free of distracting elements.

Along with information overload, stylisation (i.e. the subjective rendering of entities, actions and phenomena) is the chief GA distraction. Scientist bloggers ${ }^{9}$ have complained about the ambiguity and trivialization present in the representation of scientific contents in GAs, described by some as "cartoons without captions" and "more amusing than instructive". Colour, for instance, may be employed arbitrarily, without any expected functional criterion, in molecular renderings, sometimes shaded out of aesthetic purposes that mislead readers into believing that the shading is marking specific bond areas ${ }^{10}$. Or molecules may be drawn with cartoonish facial and bodily features that downplay and trivialise the scientific message and are conspicuously superfluous ${ }^{11}$. This form of trivialisation has been termed 'molecule prettification', and may be accompanied by font types (e.g. Comic Sans) that magnify the overall infantile effect.

It is indeed striking that specific rendering prompts come mostly from individual initiatives such as academic forums and Q\&As sections in academic network websites. In Researchgate ${ }^{12}$, for example, the thread of the responses to the question "How to create a GA?", posted by an Indian researcher in technology on January 3, 2015, evinces three facts: first, that the need to encode technical research visually has arisen relatively late among Researchgate users, given that Elsevier launched the "Article of the Future five years ago. Second, that many respondents admit to not having heard of the genre so far, and a couple of them even mistake GAs for 'geographical abstracts' and posters. And third, only two suggestions send the reader to the Guide for Authors pages of Elsevier and JoVE ${ }^{13}$ (Journal of Visualized Experiments), the world's first peer-reviewed scientific video journal, established in 2006. Another three entries (out of the twenty-one uploaded in February 2016), inform of software tools for drawing blending or blending 3D pictures (animations).

\footnotetext{
$5 \mathrm{http}: / /$ editorresources.taylorandfrancisgroup.com/taylor-francis-online-graphical-abstracts-and-first-page-previews/

6 http://www.tandfonline.com/toc/lsyc20/current

7 http://www.fems-microbiology.org/journals/graphical-abstract.html

8 http://www.cell.com/pb/assets/raw/shared/figureguidelines/GA_guide.pdf

9 http://www.rheothing.com/2010/05/graphical-abstracts.html; http://blogs.nature.com/thescepticalchymist/2011/07/ the_art_of_abstracts.html

10 See the GA in http://onlinelibrary.wiley.com/doi/10.1002/anie.200904588/abstract

11 See the GAS in http://pubs.rsc.org/en/Content/ArticleLanding/2011/CS/C005424K\#!divAbstract and http://pubs. acs.org/doi/abs/10.1021/om3007213

$12 \mathrm{https}: / / \mathrm{www}$. researchgate.net/post/How_to_create_a_graphical_abstract

$13 \mathrm{http}: / /$ www.jove.com/about
} 
Predictably, the video research article has eventually come to attach video abstracts in animation of filmic narrative format, and $\mathrm{Ce}^{1 / 4}$ has once again pioneered the issuing of style guidelines for authors online. Posted in 2015, they recommend the use of schematics and a minimum amount of raw data and figure panels to communicate findings. Videos should include legible texts as regards font size, last less than five minutes, and be contained in a flash player window to be uploaded in the journal's YouTube channel. Furthermore, filmed slideshows with voiceovers (usually the authors') explaining the data are discouraged in favour of videos made for the purpose, and specifications for their preparation concern the size of files and frames, frame-rate $(30 / \mathrm{sec})$, formats (e.g. mov, mpg, avi, mp4), etc.

Surprising as it may seem, 'trivialisation' effects are present in this genre variant as well, since three video instances presented by the journal as good examples are adorned with singular musical backgrounds (tango, folk, and cartoon-like melodies) that might induce us to question the rigour or 'seriousness' of the videos' objectives. Likewise, their respective informative progressions are genre appropriations that cause, Bhatia (2014: 111) holds, "interdiscursive relations" across professional genres, practices and cultures. The tango music matches a sort of hard-boiled video clip filmed in black-and-white, in which researchers play the role of detectives from the 1940s with the mission to capture carcinogenic elements that escape an anti-angiogenic treatment. The cartoon-like tunes feature the folding process of the human genome into the nuclei of cells with an aesthetic approach that resembles clay animation movies, and the folk guitar strumming introduces a monologue and later a dialogue between two Biology researchers engaged in the investigation of the symbiotic microorganisms of cicadas, with an atmosphere reminiscent of the 'Get a Mac' campaign of Apple commercials between 2006 and 2009. All these appropriated discursive traits are, no doubt, dispensable, and trigger a string of questions that need sustained ethnographic research, cross-cultural reception studies and academic consensus to be answered: Is such discursive appropriation really trivial? Why is 'trivialisation' more welcome in multimodal formats than in mono-or bimodal ones? Is subjectivity to be then acknowledged as an asset in transduction? Should we consider it as inherent in video abstracts? And in those GAs that include animations, and hence have an intermediate status between the still image and the filmic sequence?

Because of their textual and social features, in sum, GAs may be categorised as hybrid practices halfway between the verbal and the visual, mimesis and creation, conventional and structured abstracts (as they may contain labels and headings), symbiotic (to the verbal text) and stand-alone meanings, objectivity (of the scientific content) and subjectivity (in the representation), and disciplinary specificity and interdisciplinarity. Their academic function ranges from that of science dissemination or pedagogical tool to advertising lure and digital decoration, and the symbolic and naturalistic representations they may contain embrace photography, diagrams, graphs, art, animations and film, and their diverse, culture-bound and subjective nature may make genre recognition difficult. The question is: Can GAs be truly called genres, if full social recognition is a must for social practices and their texts to be regarded as such? Because unless communities of practice agree upon strict GA conventions and standards, the visual encoding and decoding of material of the three strata that integrate any full-blown semiotic mode (Bateman 2011), that is, of the material substrate, the semiotic resources and discourse semantics, depend more on individual abilities than on professional expertise. This consequence, as I have pointed out elsewhere (Sancho Guinda 2015), may disintegrate long-established professional communities rather than strengthen their bonds. Or, more accurately and as commented in the previous subsection, it may distinguish a new type of community of practice - a multiple membership aggregate that is more diversified, transient and permeable. At present, though, it seems that this labile interdisciplinary community is confined to the 'tribes' of Elsevier, Taylor \& Francis and FEMS readerships.

$14 \mathrm{http}: / /$ www.cell.com/video-abstract-guidelines 


\section{Data and method}

Having ascertained the graphicacy background fostered at the ETSIAE as regards the function of visuals and the type of task (subsection 1.2), I turn now to the main body of this study, which pivots around one central question: How do my engineering students codify science visually, without having been trained? More specifically: what 'semiotic shortcuts' do they spontaneously resort to, in order to economise information?

To find an answer I asked a class of fourth-year aeronautical engineering students, all of them with an accredited B2 level of English, to design a graphical abstract of a particular laboratory practice they had conducted in their second year and which I had filmed. They were allowed to use any visual technique, including compositions with any of the 2,401 photograms initially extracted from the video, whose duration was 1'36". From those photograms, a basic kit of 20 was confectioned with some of the shots most representative of each of the eleven steps. This reduction of the number of images was intended to ease the identification of moves and steps and simplify the choice of representative shots. Without any scaffolding or training in GA design, the students produced a corpus of 56 individual samples. Their candid, unscaffolded approach to the task would allow me to see whether they could arrive at the basic principles of Kress/van Leeuwen's (1996) visual grammar by discovery and also work out original meaning-making strategies.

The laboratory practice selected (due to its brevity, simplicity and memorability) was the procedure of surface preparation for adhesive bonding in aircraft construction. Choosing a procedure (i.e. a method that follows an invariable sequential pattern) ensured a certain degree of 'rhetorical homogeinity', thanks to which variation would in principle be more easily assessed than in a full IMRD argumentative structure, more susceptible of ambiguous move fusions and embeddings. In a procedural description, students had just to focus on a single move, the method, and encode its stages and steps in the fashion they deemed pertinent, although by definition methods arouse the expectation of an orderly (that is to say, chronological) narrative arrangement of stages and steps. Optionally, to enrich their texts students could incorporate extra-narrative material: an introduction to the importance, background or state-of-the-art of adhesive joints, or a move displaying and/or discussing the results of the tensile test to be conducted after the surface preparation-. As a reminder, the following introductory information was facilitated, which could be included visually or verbally (in a very succinct form):

\footnotetext{
"Adhesives are used in the aerospace industry because they offer multiple and well-documented advantages. For example, with them engineers can assemble dissimilar materials and heavy weight loads, improving the uniform distribution of the stresses and strains across bonded joints. Adhesives also maintain the integrity and strength of materials as there is no hole, rivet or fastening elements such as bolts, nuts, or screws to weaken the structure."
}

Before proceeding to GA design, students watched the video several times and collaboratively completed the flow chart below, as a road map to their visual creations: 


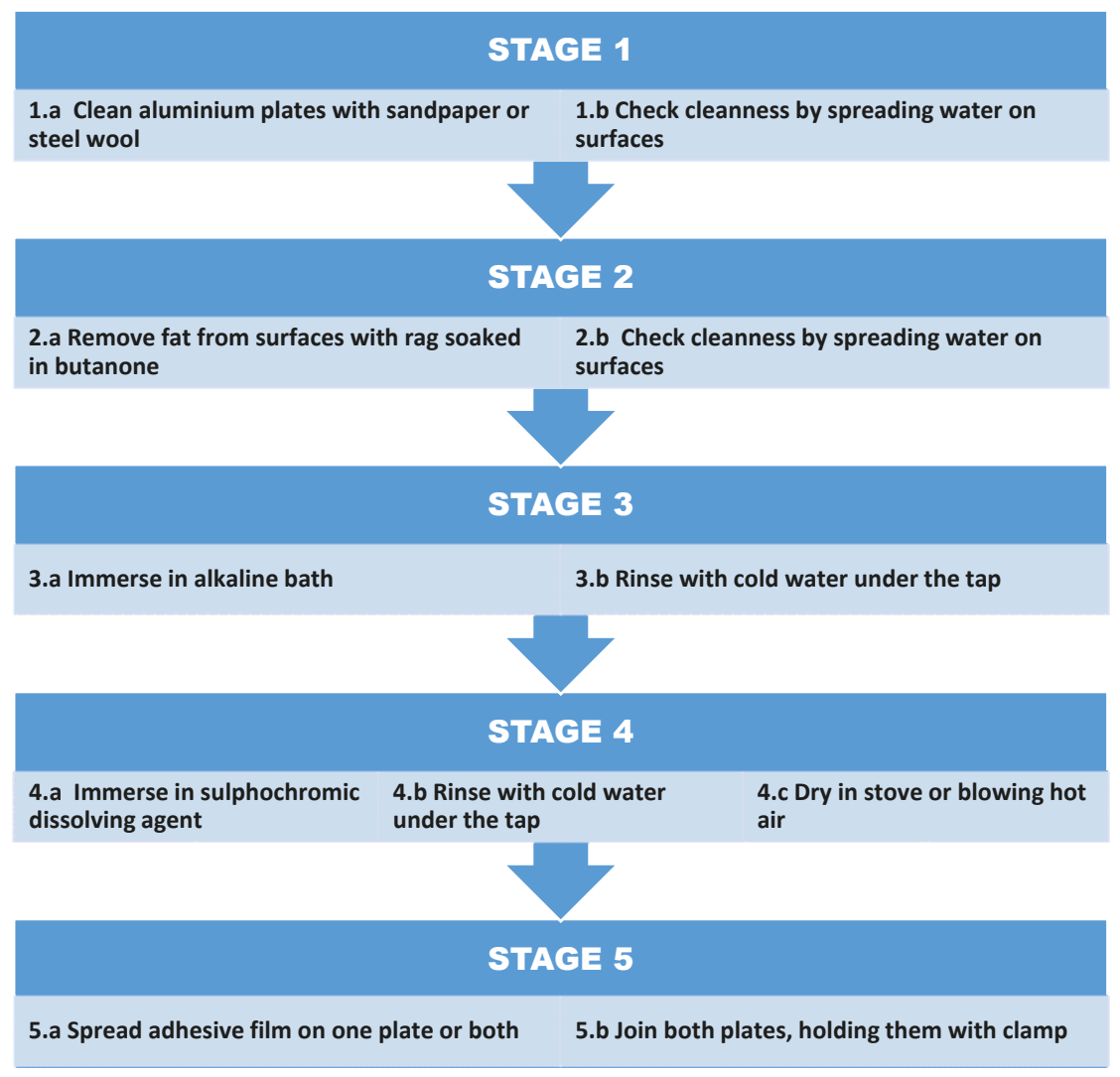

I analysed their GAs attending to the medium, format, type of representation, guidance devices employed, and instances of authorial subjectivity. The medium is the material resource employed in the production of the semiotic product (Kress/van Leeuwen 2001: 21-22) and may permit the use of more than one mode or particular kind of interaction, defined by Kress (2010: 79) as a "socially shaped and culturally given semiotic resource for making meaning in representation and communication". Examples of modes are image (still or moving), speech, gesture, writing, music, and 3D objects. The format category encompasses storage or display arrangements fit for a given medium (e.g. ready-made or self-designed software if the communication or representation is computer-mediated, as is the case here), and the type of representation is determined by the degree of naturalism in the depiction of reality (e.g. 'realistic', 'schematic', 'metaphorical'). Under the term guidance devices I subsume those items (e.g. frames, lines and vectors) that indicate reading paths, chronology and cause-and effect relationships, and are equivalent to elementary verbal metadiscourse. The last category for analysis, subjectivity, can be tracked in diverse types of 'stylisation' (i.e. renderings prompted by individual preferences), 'directionality' (i.e. reading paths) and 'register shifts', which alter the tenor of the interaction by lessening its formal nature. A recapitulative inventory of students' semiotic strategies ('shortcuts') based on this coding will be presented later on. It will be divided into 'items' and 'composition strategies'.

\section{Findings: students' encodings}

The students who participated in this study were (and still are) a discursive community in the making, characterized by their flexibility and readiness to learn and use new technologies, yet a long way away from constituting a full-fledged engineering community of practice. Despite their condition of 'digital natives' and the fact that they had not received any creative prompts nor had they been imposed any restrictions, the format of their GAs was, as we will see, less innovative than expected. 


\subsection{Medium, format and representation}

None of the samples incorporated audio or video, and only one made use of animations, although the bulk of students was familiarised with animation tasks and tools (e.g. the different versions of the freeware program Blender for 3D animations), taught in a very popular elective subject matter at the ETSIAE. This conservatism on the students' part is patent in Figure 3, which shows that the highest proportion of samples was submitted in monomodal and conventional Word or PDF file formats, as any verbal assignment is. Much lower percentages correspond to PowerPoint and JPG formats, and, curiously enough, nine samples - three PowerPoint GAs and another six Word/PDF ones - exceeded the standard one-panel extension, as they respectively consisted of two, six and eight slides (each slide functions as a panel) and had a length of two to five pages (pages are larger than the average panel size). By analogy with verbal abstracts, which four-year students have already handled, the informants could have suggested more synthetic renderings, but a few preferred to reproduce the practice in full detail, regardless of the summarising function of the genre.

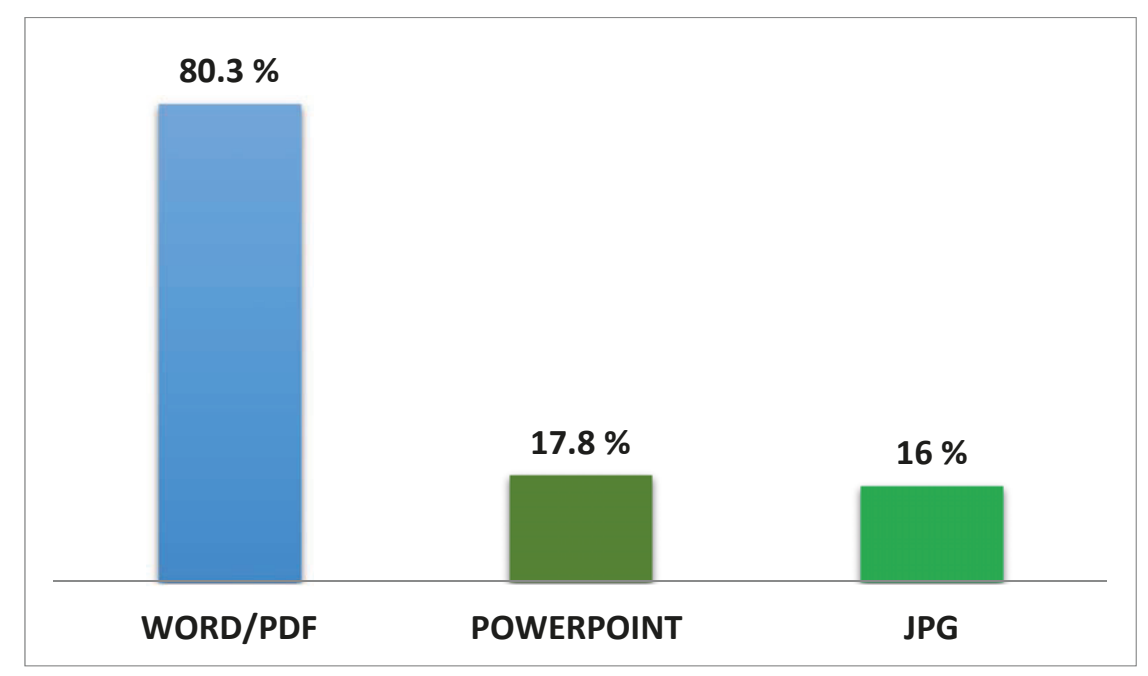

Figure 3. Format of the samples submitted ( $\%$ of samples)

By and large, the type of representation preferred was a blend of realistic (i.e. photos), schematic (i.e. reductive representations such as graphs, diagrams and tables) and, occasionally, metaphorical depictions. As was reasonably expected, linear narratives sequencing steps chronologically by means of guiding markers, were overwhelmingly numerous among other types of design. The second kind of rendering most used was the combination of a linear narrative with a reductive representation, mostly graphs (10.7\% of the narratives using combinations). In comparison, the percentage for combinations of linear narratives with drawings, diagrams and graphs, and with diagrams associated with graphs and tables was dramatically low (3.6\%). Even lower, and also identical $(1.7 \%)$, were the proportions of linear narratives combined with diagrams and with tables and graphs together. 


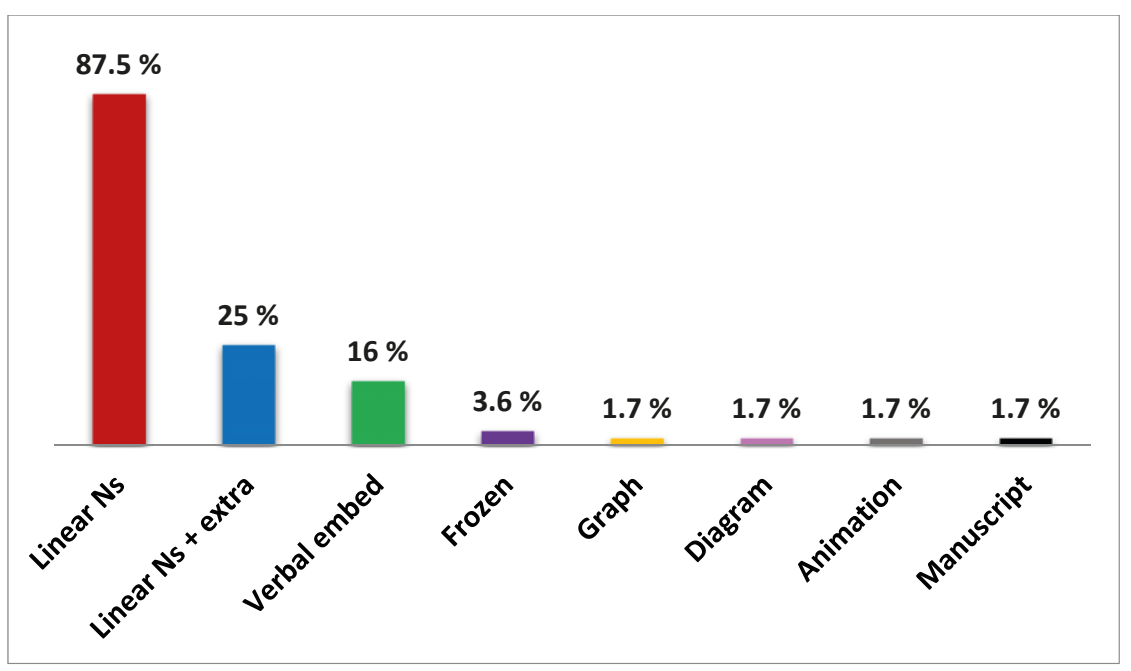

Figure 4. Format of the samples submitted ( $\%$ of samples)

A few samples embedded the visuals as illustration in the full verbal description of the procedure, sometimes without legends right below the images. And a couple of cases (see Figure 5) consisted solely of a 'frozen', 'pregnant' or 'still' moment (Ryan 2004), that is, of a shot (a single frame) capturing some point of the narrative in isolation, accompanied by a one sentence legend. These 'frozen moments' condense the whole narrative into a single scene and leave it to the spectator/ reader to unfold the shot into a story, which is evoked instead of told. The final effect is comparable to entering the narrative 'in medias res' (Ryan 2004: 140).

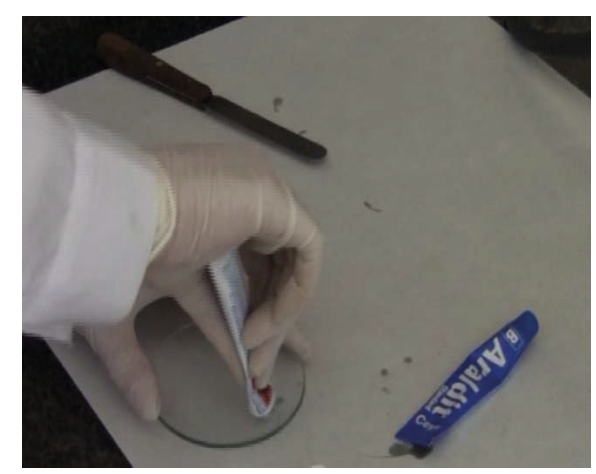

The two components of the adhesive are mixed

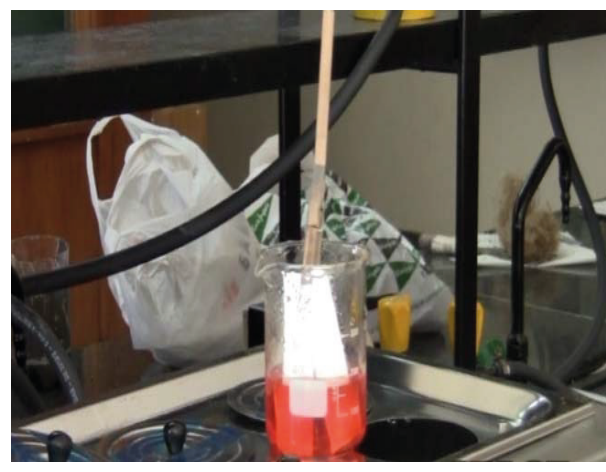

Plates are introduced in a sulphochromic bath in order to clean the contact zones

Figures 5A-5B. Frozen moments (two different GA samples)

Extraneous frozen moments were found inserted in some linear narratives (seven instances). Precisely because they are not part of the narrative and are out of the time and/or of the space when and where the process is narrated, I have called them achronies. Their function is to contextualize the upcoming reporting, justify its importance, or refer to future events outside the current narrative. In the sample displayed by Figure 6A we may spot two achronies: a contextualising one showing the aluminium plates to be joined, before the telling proper starts, and the other advancing the tensile test to which the bonded plates would be subjected, once completed the surface preparation and assembling procedure. It should be noted that the picture of the assay machine was not included in any of the photogram kits. The two achronies in Sample 6B fulfill the same functions: a contextualization in the form of a table enumerating the materials needed at each 
stage, and a graph with the results of the tensile test. More achronies can be found in the sample of Figure 19, and in a pair of samples there were images of aircraft in flight and of plane crashes to corroborate the essential role of adhesive joints and the need for their periodic maintenance.

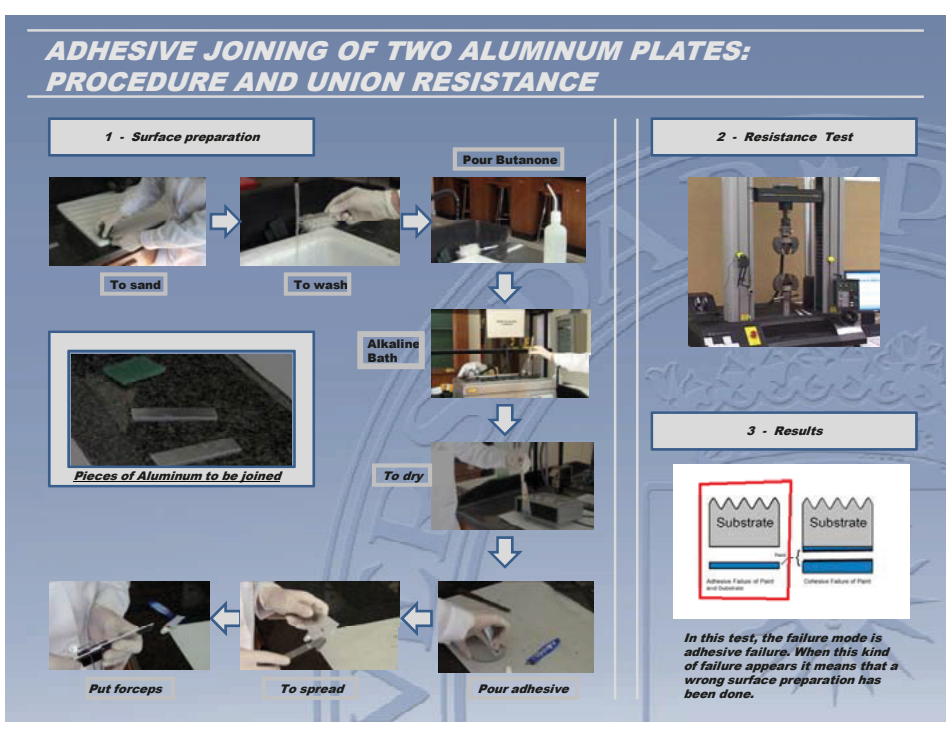

Aluminium plates glued (adhesive)- Tensile test

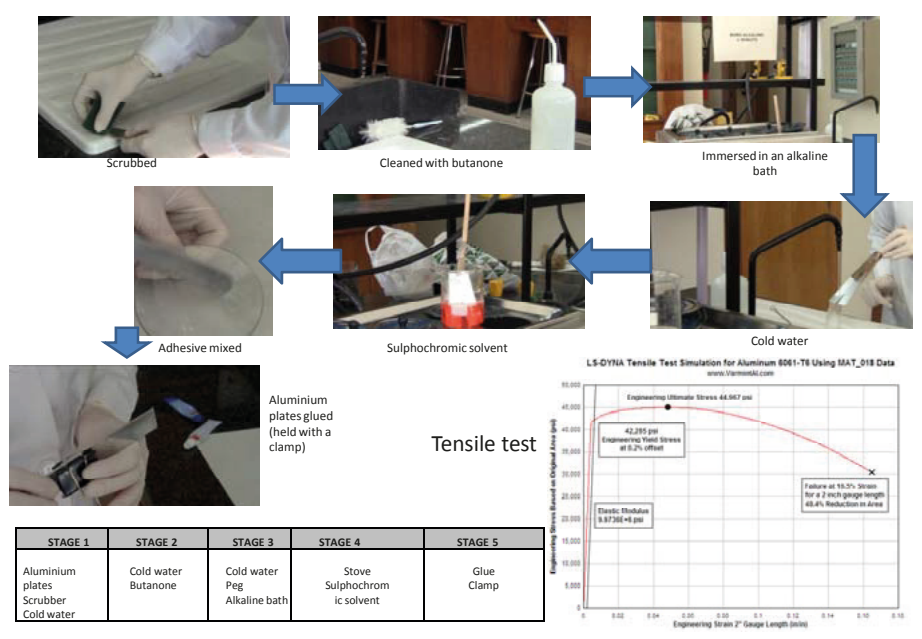

Figures 6A-6B. Linear narrative samples with two achronies

As to the other representations in the bar chart of Figure 4, they yielded very small and exactly the same percentages of use. Line graphs, paradoxically, are dynamic because they depict a trend - the evolution of a certain variable over time - but at the same time reductively compress that narrative in one frame and the reader must recompose the original progression of actions, which is merely evoked. The graph title, legend and axes' labels in the plotline of Figure 7 contribute to this narrative reconstruction, but all of them point simultaneously to an achrony: the assays subsequent to the procedural narrative of surface preparation and adhesive bonding. 


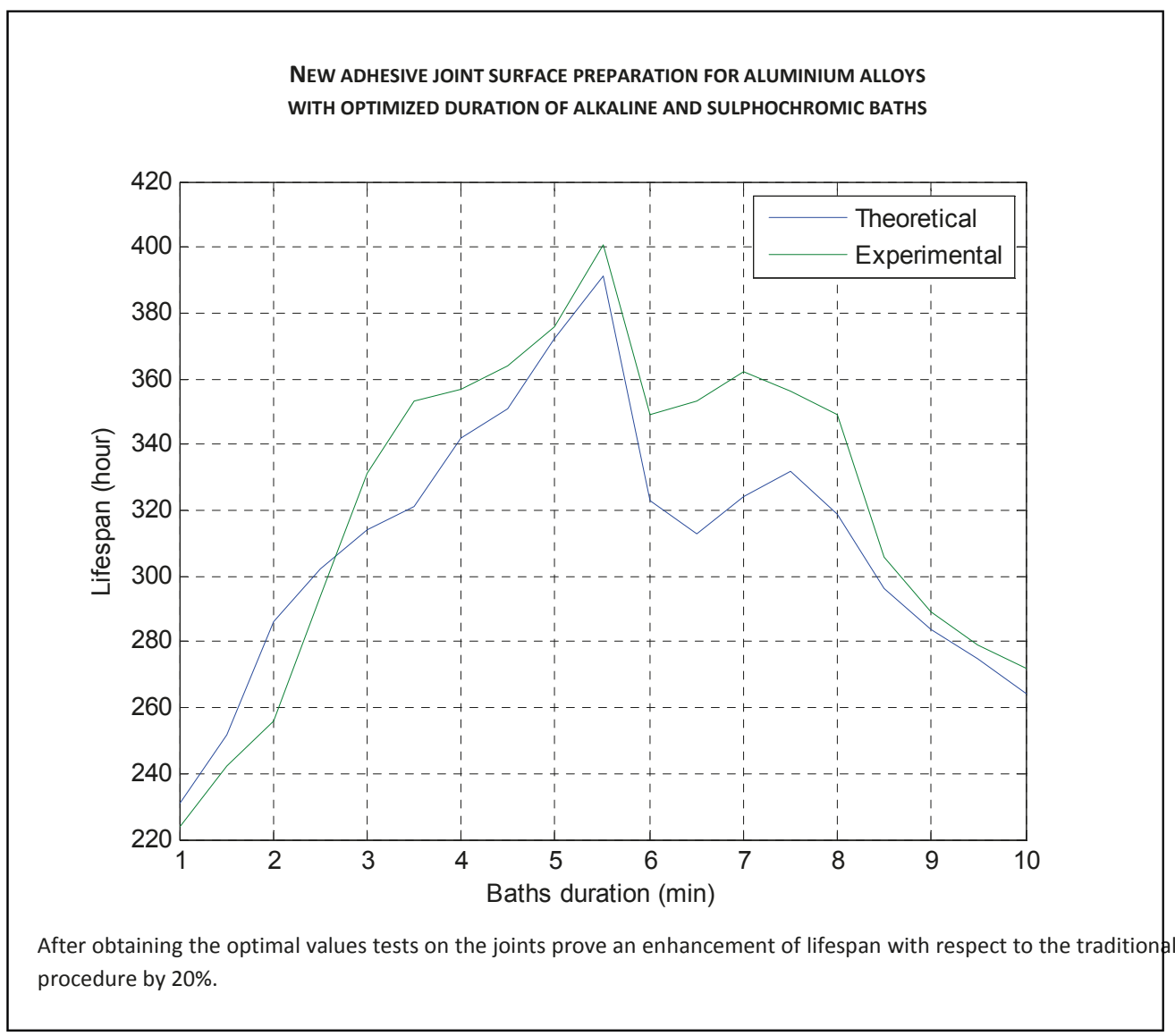

Figure 7. Graph-type GA sample 

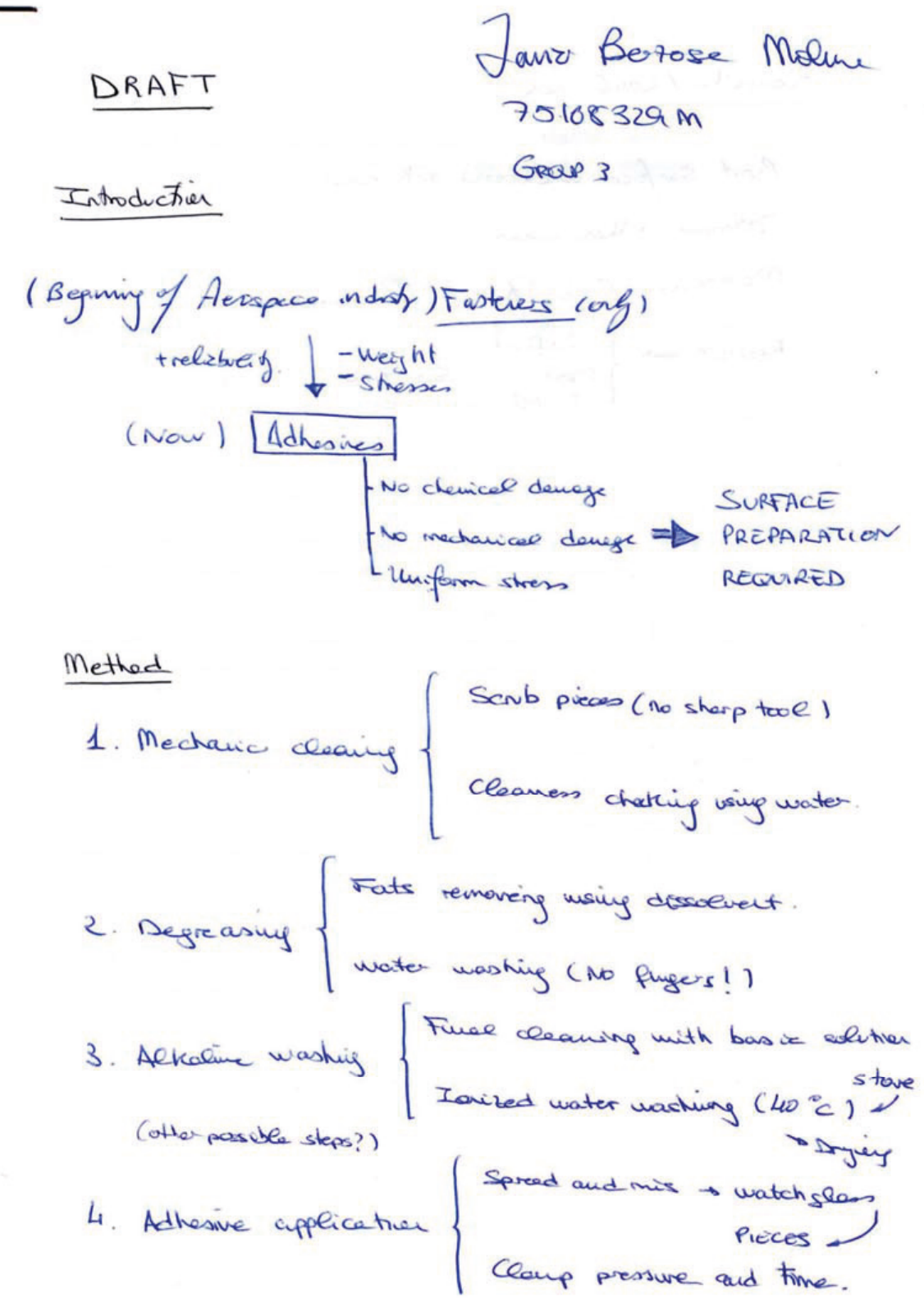

Figure 8. Manuscript GA

Similarly, the GA in Figure 8 separates and numbers procedural steps to sequence them and there is a dual narrative progression from top to bottom and from left to right, but the general impression is static and the vectors or 'verbal verbs' (Kress/van Leeuwen 1996) present on the page (two arrows, numbers and several curly brackets), do not suffice to overcome the stasis effect. The explanation is simple: the salience or 'eye-catchiness' of the composition is low because the verbal text, although visual, is not minimally iconic of the actual actions it denotes, and the curly brackets are more suggestive of conceptual classification than of the temporal proximity and cause-andeffect relationship of the two consecutive actions they embrace.

The partial conclusion to be drawn from this subsection of the study is that students tend to encode the procedural narrative in a conservative fashion: using a single mode (static image) and 
with a realistic-schematic arrangement of stages and steps, sometimes disregarding the encapsulating objective of the genre. In this sense, they incur either incompleteness or excessive informativeness. The former is caused by the use of de-contextualised frozen moments, and the latter by the inclusion of achronies whose role and place in the narrative sequence are insufficiently explained to the reader.

\subsection{Visual metadiscourse}

What visual devices serve as metadiscourse surrogates? In equal percentages (see Figure 9), a vast majority of students used frames and vectors as overt metadiscursive guidance. According to Kress (2010), framing is essential to meaning-making because it includes and excludes and defines the world to be engaged with, the boundaries to interpretation. He stresses that there is no meaning without frames, which confer completeness to the text. On her end, Ryan (2004) reminds us that framing segments the big picture into smaller units (panels), under the assumption that adjacent frames/panels represent subsequent moments and causality is deduced from the states depicted in the frames. In multi-framed narratives, which enable us to tell more complex stories than in frozen moments, the reader/spectator must move the eye from one panel to the next to keep the narrative flow going. In my corpus this flow was sustained by an average amount of 9.7 frames per sample, which indicates that students were close to devoting one frame per step, thus constructing detailed animation-like narratives, with a short temporal distance between scenes. Most frames were 'dynamic' in the sense that they captured instants at which a gloved hand was performing a certain action, instead of an intermediate frozen moment immersed in the chain of events. However, this faceless trace of human intervention, of agency, metaphorises (consciously or not) the impersonality required in procedural descriptions and usually embodied by the passive voice. Only $23 \%$ of framed samples contained shots without this metonymyc human agent.

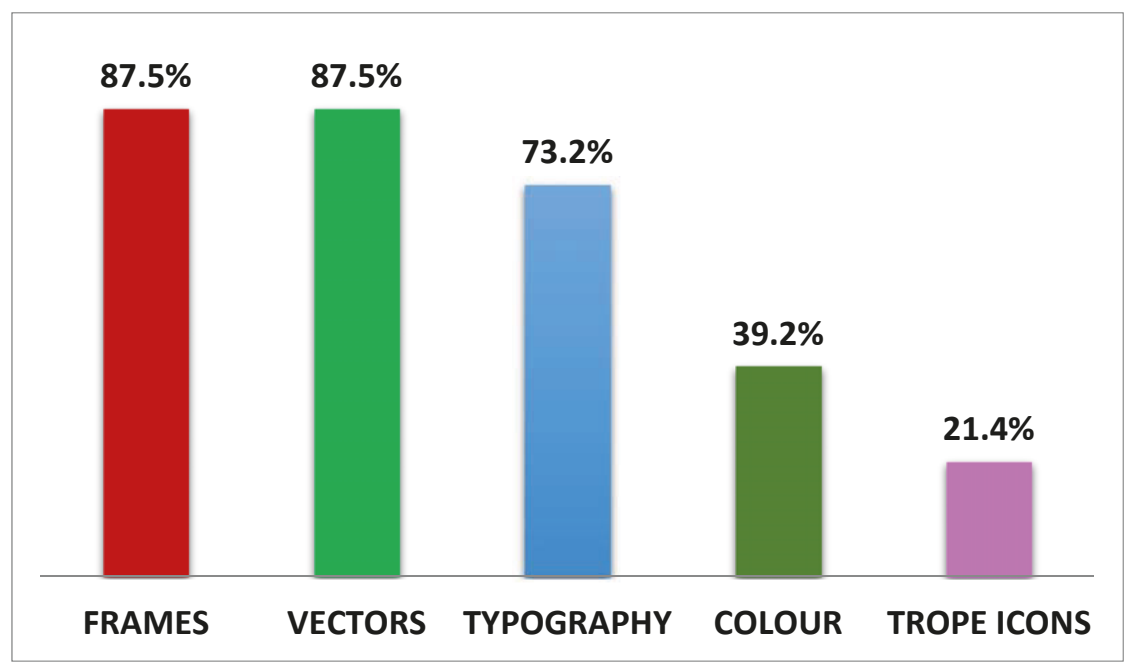

Figure 9. Guidance devices ('metadiscourse surrogates') in GA samples

To guide readers from frame to frame and signal an intended reading path, students used vectors, predominantly arrows (Figure 10). Frames, arrows and captions underwent substantial stylisation in their size, colour, shape and composition to tease out major steps (i.e. the successive chemical baths and the adhesive application) from minor or recurrent actions (e.g. the recurrent water rinses, as can be observed in Figures 11 and 12), and the average number of vectors per sample (6.9) was relatively high to mark the transitions between frames along the eleven-step narrative, although overlapped frames may be sporadically arranged as an alternative to directional vectors (Figure 11). This metadiscursive concern makes students' GAs highly reader-oriented or 'engaged' (Hyland 2005). 


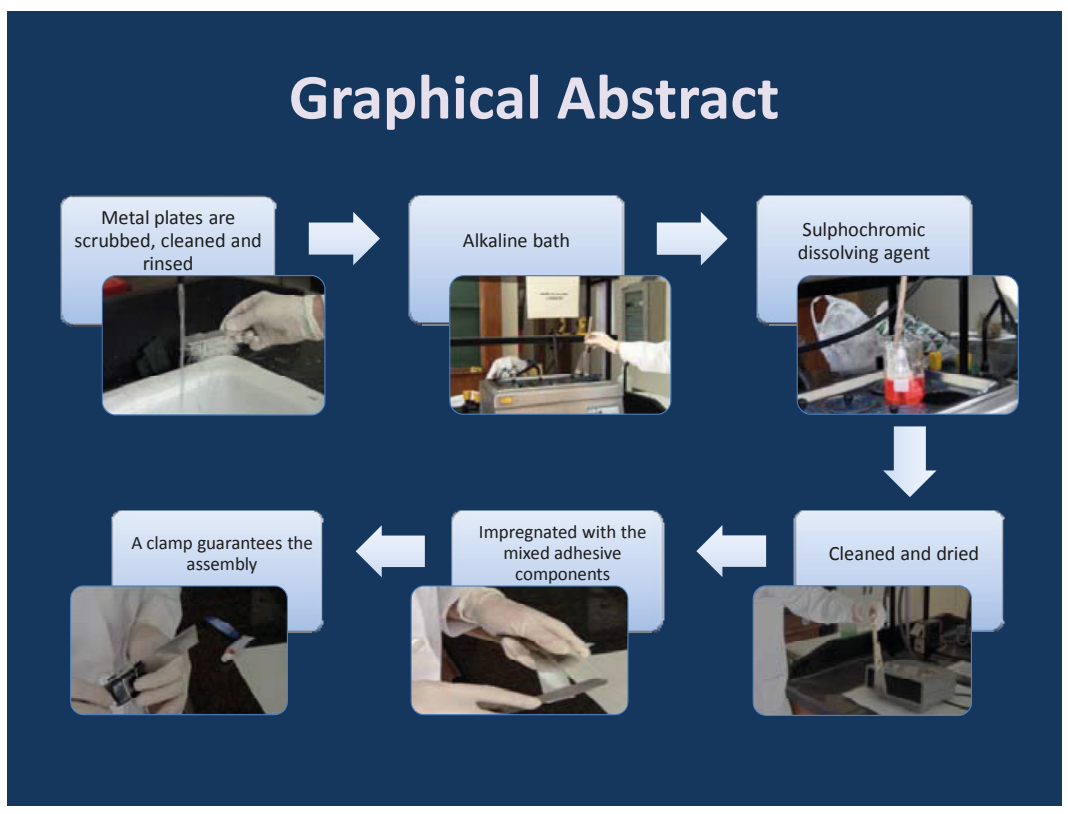

Figure 10. Prototypical linear narrative with vectors and verbal text

\section{ADHESIVE PROCESS IN AEROSPACE INDUSTRY}

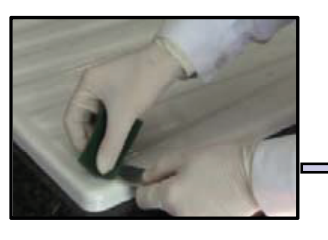

1. Scrubbing

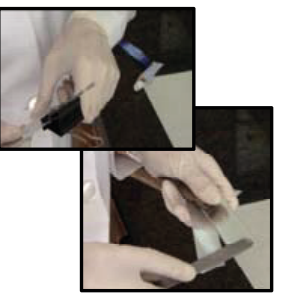

6. Glue application and holding

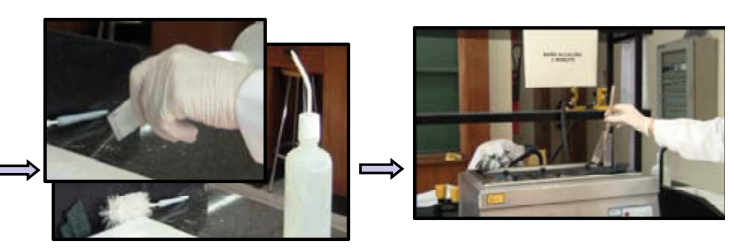

2. Butanone cleaning

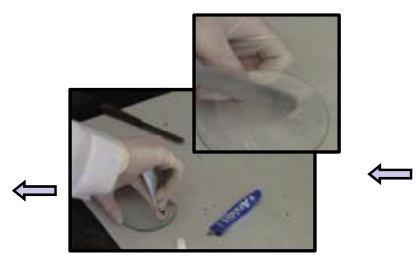

5. Glue mixing
3. Alkaline bath

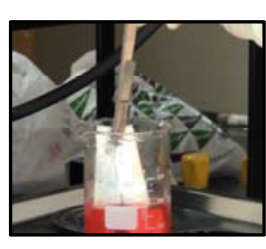

4. Sulphochromic bath

Note: after stages 1,2,3 and 4, the pieces must be rinsed with water

Figure 11. Overlapped frames as an alternative to vectors 


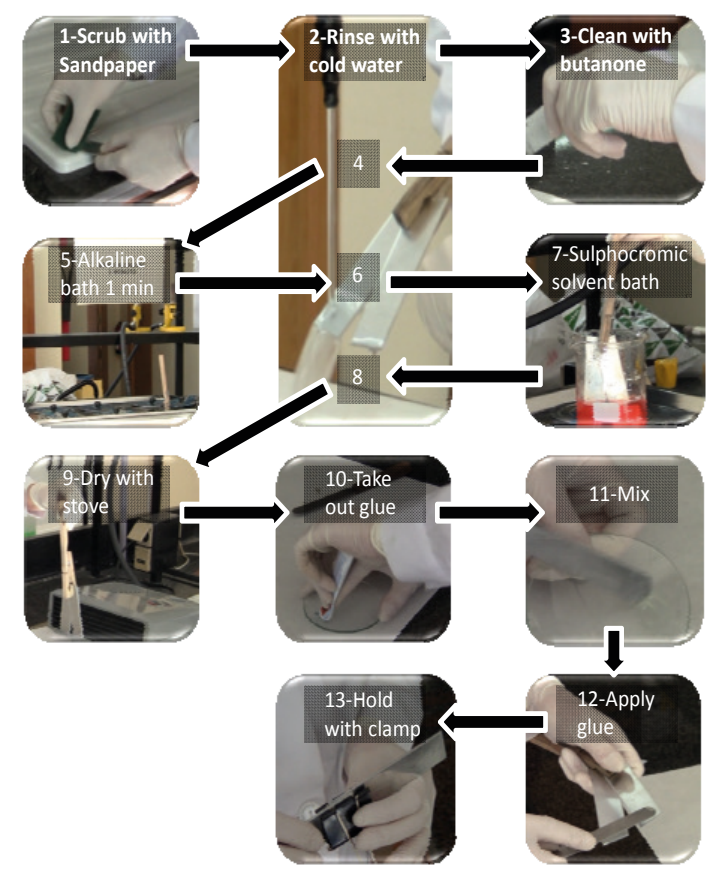

Figure 12. Linear narrative with vectors and clustering of recurrent actions

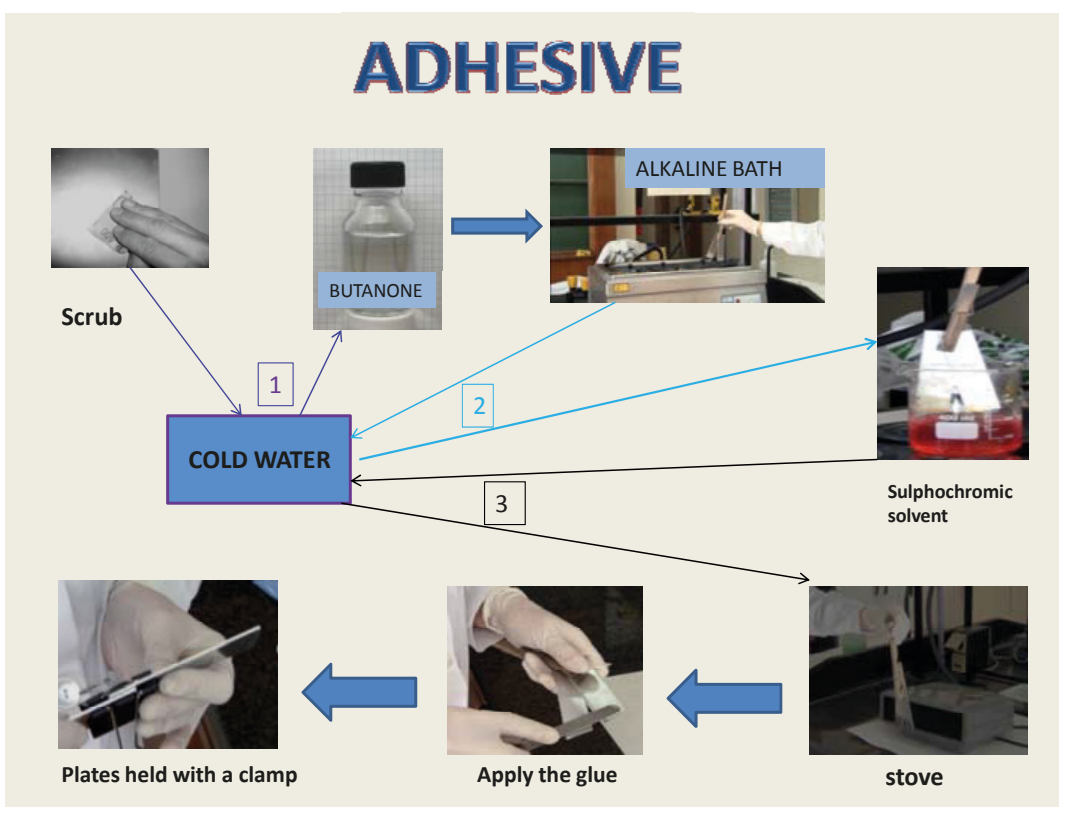

Figure 13. Linear narrative with vectors and clustering of recurrent actions with a radial-central composition

In addition to arrows, mathematical signs (Figures 14A, with two achronies, and 14B, with another contextualizing one) proved effective resources to highlight clusters of actions temporally near or causally related. This mathematical encoding, which is but a code shift, spares a considerable amount of verbal text, guarantees universality in the interpretation, and furnishes meanings other than sequential: cumulative outcomes or similarity, causality, and shorter time spans between steps. 


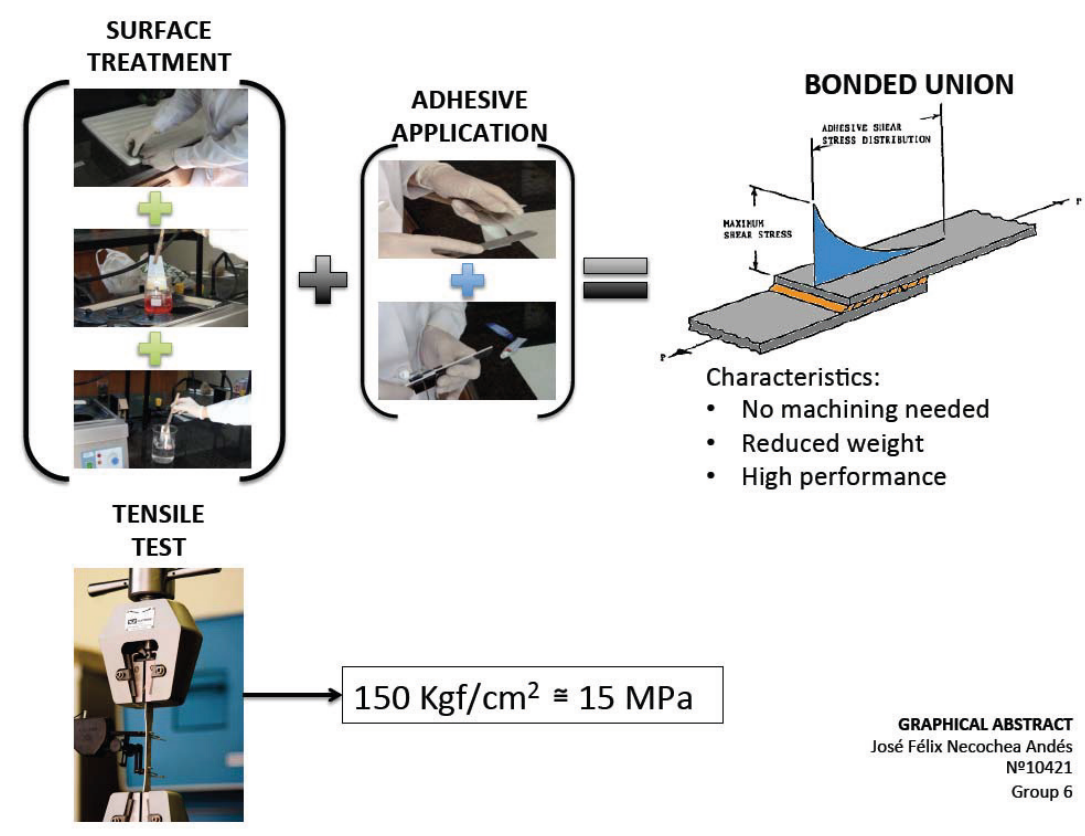

Graphical Abstract

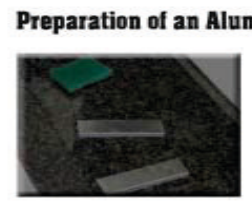

m Plate:
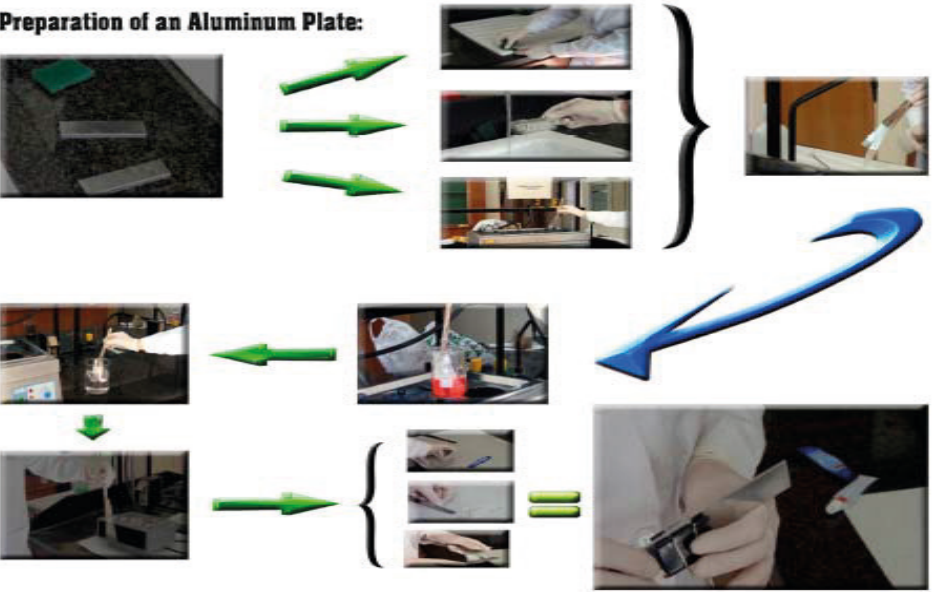

Figures 14A and 14B. Mathematical encodings of the procedure

Typography is also massively used, above all boldface, capitals, and font size to underscore importance, whereas italics, underlines, shadings and font type were very secondary options. 


\begin{tabular}{|c|c|}
\hline TYPOGRAPHIC DEVICE & PERCENTAGE OF SAMPLES (\%) \\
\hline Boldface & 42.8 \\
\hline Capitals & 39.2 \\
\hline Font size & 32.1 \\
\hline Italics & 5.3 \\
\hline Shadings & 1.7 \\
\hline Font type & 1.7 \\
\hline
\end{tabular}

Table 1. Use of typography as guidance device

Colour may equally turn into a signifier if functionally employed. It appeared in $39.2 \%$ of instances and more or less subtly conveyed assorted meanings: time progression (such as the gradual fadeout enhancing the vector's dynamism in Figure 15), although it may go unnoticed to the reader or pass as an aesthetic device, a distinctive nature of steps or elements, especially applied to arrows and internal cluster signs (14A, 14B and 16), lines (Figure 13), captions (Figures 10 and 13) and to different graph variables (Figure 7). Harmonic hues like the ones in Figures 10 and 13 connote unity or visual cohesion and contrast starkly with the overloaded and distracting backgrounds of Figures 6A and 16.

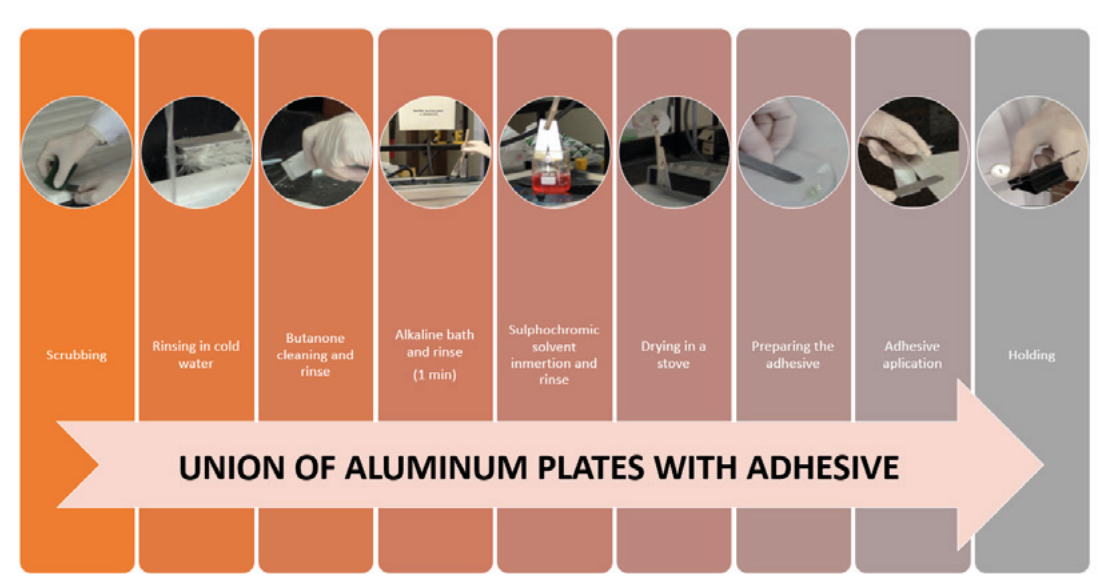

Figure 15. Chromatic fadeout as temporal progression 


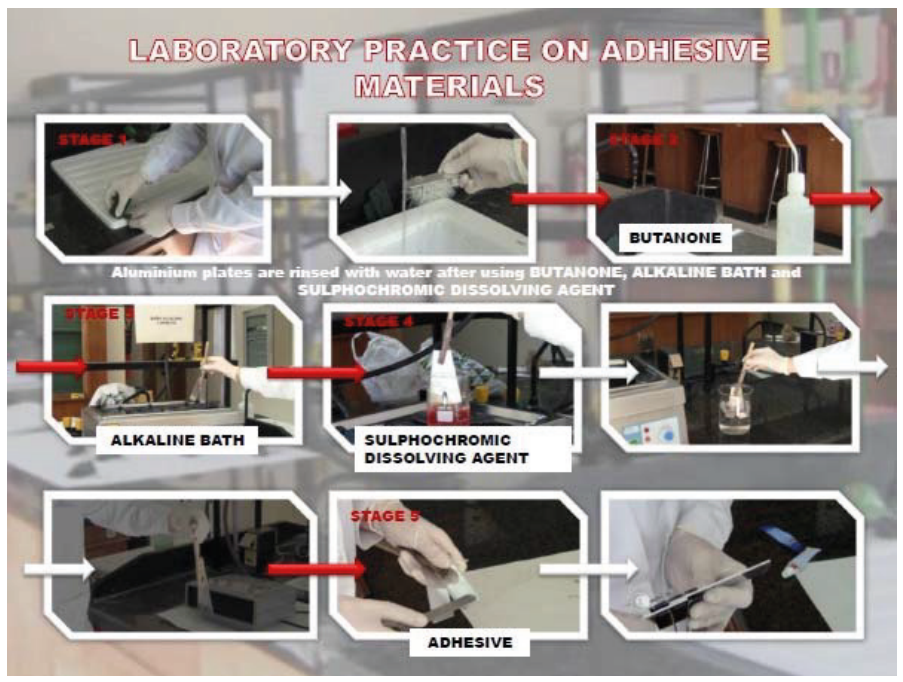

Figure 16. Distracting background

The last guidance device is what I have termed trope icons, which resemble a given referent with a varying degree of fidelity but hold a metaphorical or metonymic relationship with another real entity, concept or action. They were found in $39.2 \%$ of samples and most of them were metonymically motivated. Figure 17 is a prime example: the dripping tap icons act as labels for the successive water rinses in the procedure, and the hair dryer pictorially describes that the assembled pieces must be dried with hot blown air. The human silhouette looking at the clock explains, again metonymically, that some curing time must elapse before the glued plates are ready for the tensile test.

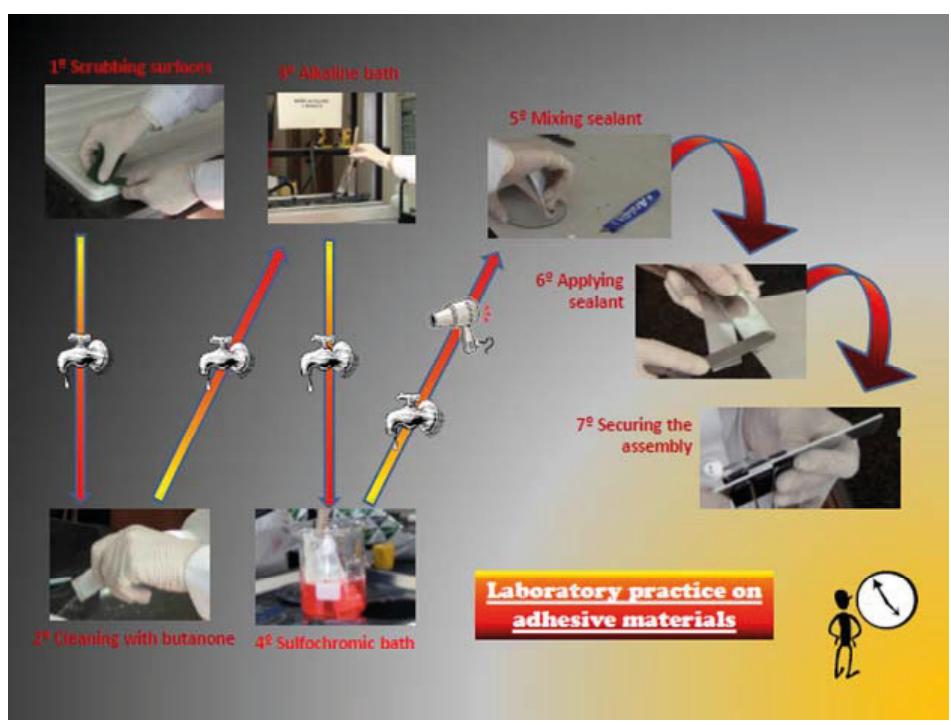

Figure 17. Linear narrative with metonymic trope icons as minor steps

In essence, students' visual metadiscourse consists of conventional frames and vectors (arrows, lines, captions) whose adjacency or spatial proximity means temporal immediacy. Yet their creative recourse to arithmetical symbology (e.g. brackets, braces, plus and equality signs) and a combination of typography, functional colouring and self-made or uncommon metonymical icons, serves to express both time and causal relationships. 


\subsection{Subjectivity traces}

Stylisation is present in roughly half of the samples (53.6\%). The footprints in Figure 18 are stylised vectors (arrows or lines) that connect frames and set the narrative pace, as do the globular frame shapes of Figure 19, whose different sizes and colours also mark importance and cluster immediate causally bound actions. The metaphorical hand-drawn stylisation of Figure 20 implies a coherent and embellished vision of the entire narrative as a 'binary tree' with a divided trunk and top - one half green as a trope of the procedure's advantages, and the other, withered, embodying its disadvantages. The text progresses deductively with a zoom-in lens gaze at the laboratory procedure as a magnified leaf, in which the different stages are listed along its nervure and iconically depicted. Stylisation carries along two big risks: misinterpretation and trivialization, two complaints common in the addressees' verdicts.

These addressees were no others than the teachers in charge of the subject matter within which the adhesive practice took place (Materials Science, taught in the second year), four female chemists (two senior lecturers in their mid-fifties and two junior teaching assistants in their mid-thirties) from the Department of Materials and Aerospace Production. In a private meeting with me to exchange impressions on the GA samples, they unanimously criticised the fragmentary uptake of both the frozen moments and the graph of Figure 7, the 'sloppiness' of Figure 8, the ambiguity of Figures 19 and 20, and especially the unsuitability of the latter for being "naïve", "childish" and "not serious" in spite of its value as conceptual map. Further, Figure 18 was qualified as "singular" and "cute" but "incomplete", and all four coincided in praising the panoramic evolution of Figure 15, above its omission of several rinses and the small size of its frames, as well as in remarking the misplaced centrality in Figure 13 and the colour saturation and label overload in Figure 24, reminiscent of arresting advertising. Opinions diverged as to the effectiveness of the only animation in the corpus and frame complexity. The younger teachers were more inclined towards frame embeddings and overlaps and multiple-framed samples with over five frames, and rated the animation as "very illustrative and efficacious", while for the others it was "stressful" and picked 'no-frills' renderings such as those in Figures 10, 14A, 14B, 22A, and 22B. This fact could be pointing to generational differences in the appreciation of visual representations, with older raters being more prone to still pictures and younger ones to motion(-like) graphics. Ultimately, the feedback given to students was a concise commentary on overall clarity, appropriacy (formality), appeal, and the existence of distracting elements hindering comprehension.

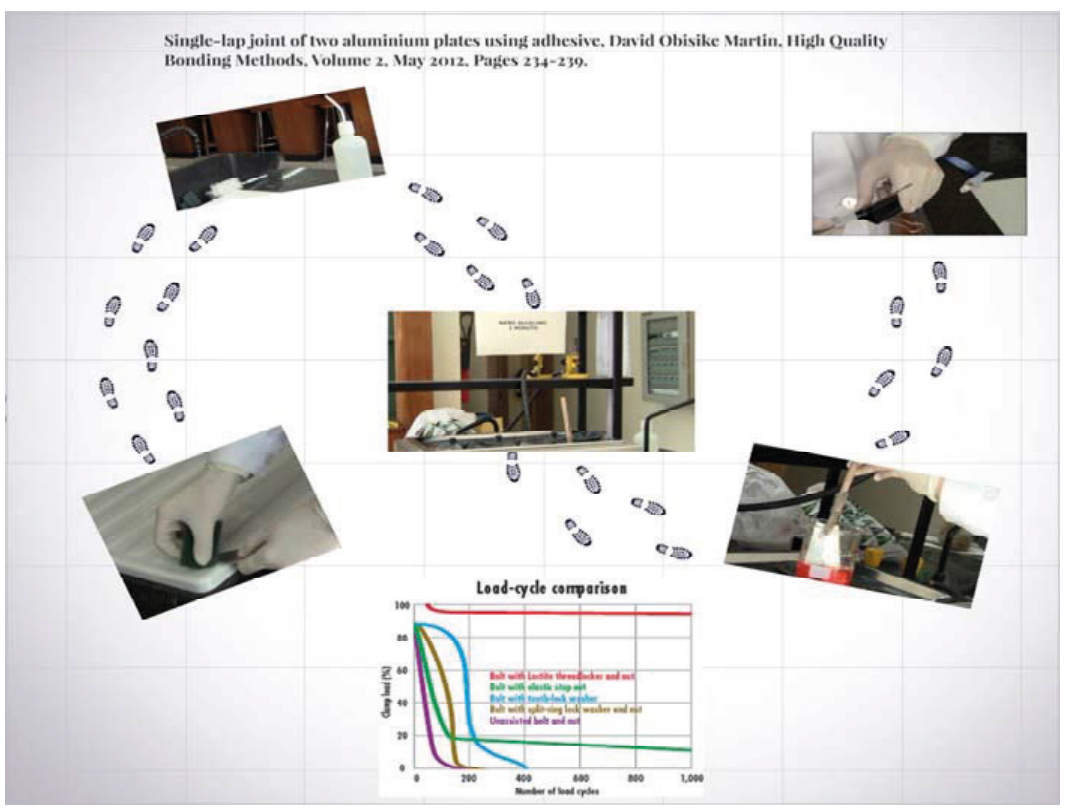

Figure 18. Footsteps as vector stylisation and trope icon 


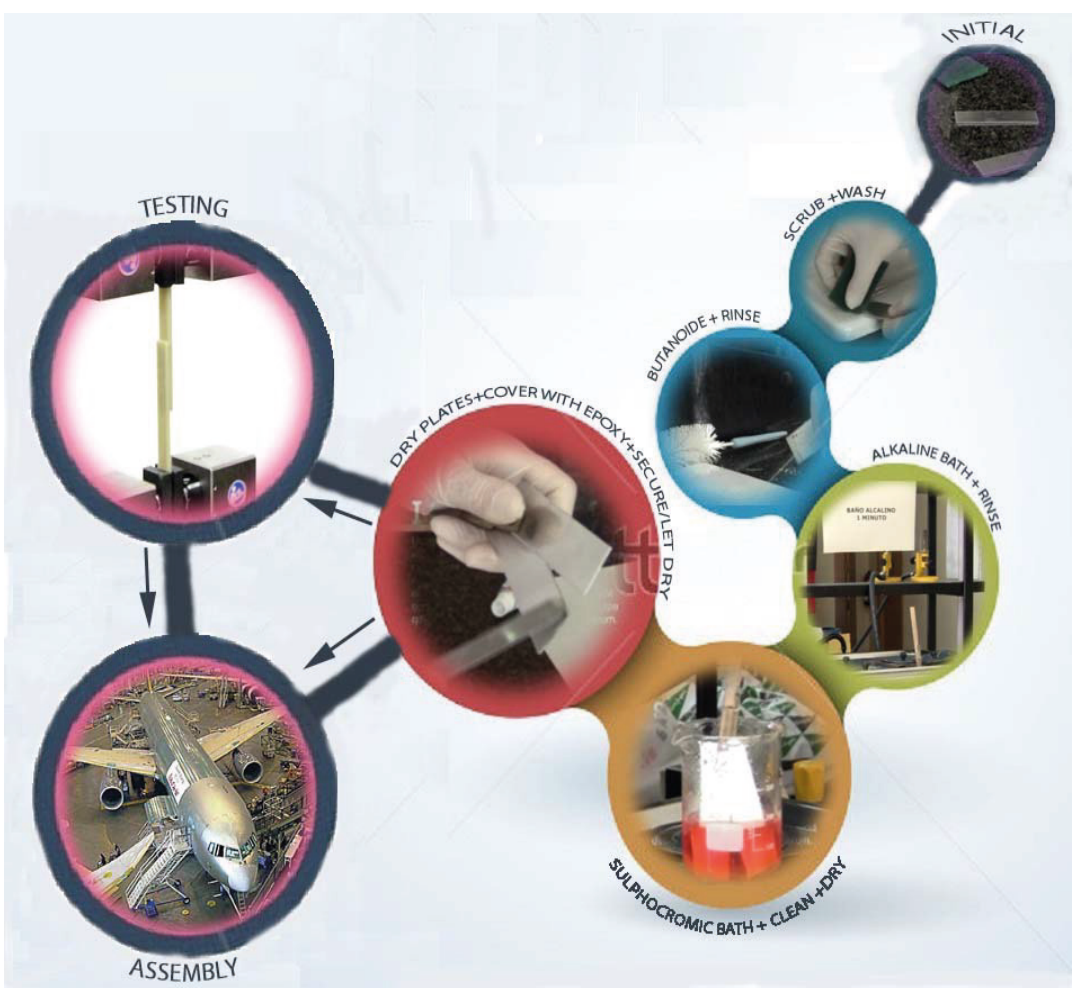

Figure 19. Freestyle globular shape as reading path
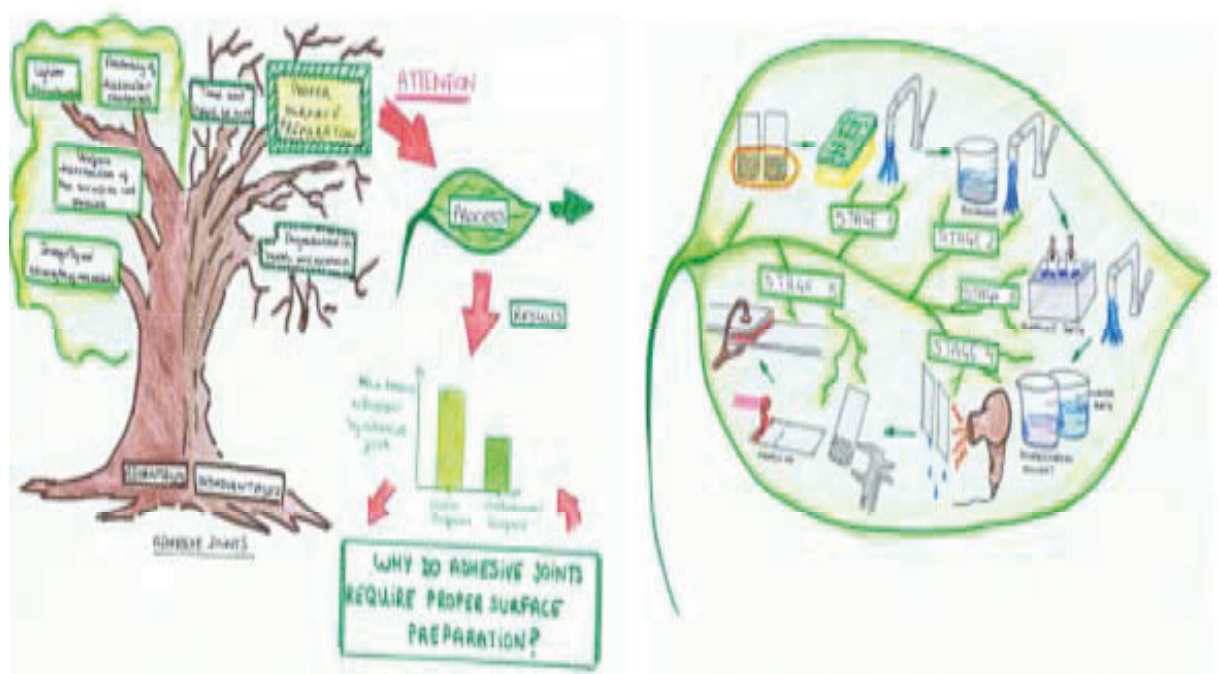

Figure 20. Metaphorical stylisation with zoom-in composition

The choice of reading paths is a culture-bound decision (Kress 2010) also motivated by individual preferences. The synergy of horizontal and vertical itineraries, that is to say, from left-to-right $(\mathrm{L} \rightarrow \mathrm{R})$ and/or right-to-left $(\mathrm{R} \rightarrow \mathrm{L})$ and from top-to-bottom $(\mathrm{T}-\mathrm{B})$ and/or vice versa $(\mathrm{B}-\mathrm{T})$ prevails over any other option, as is gathered from Figure 21. Horizontal paths $\mathrm{L} \rightarrow \mathrm{R}$ and $\mathrm{R} \rightarrow \mathrm{L}$ are nearly always in combination, and infallibly if the narrative spans over at least two rows of frames and is linked to vertical progressions (Figures 22A and 22B). 


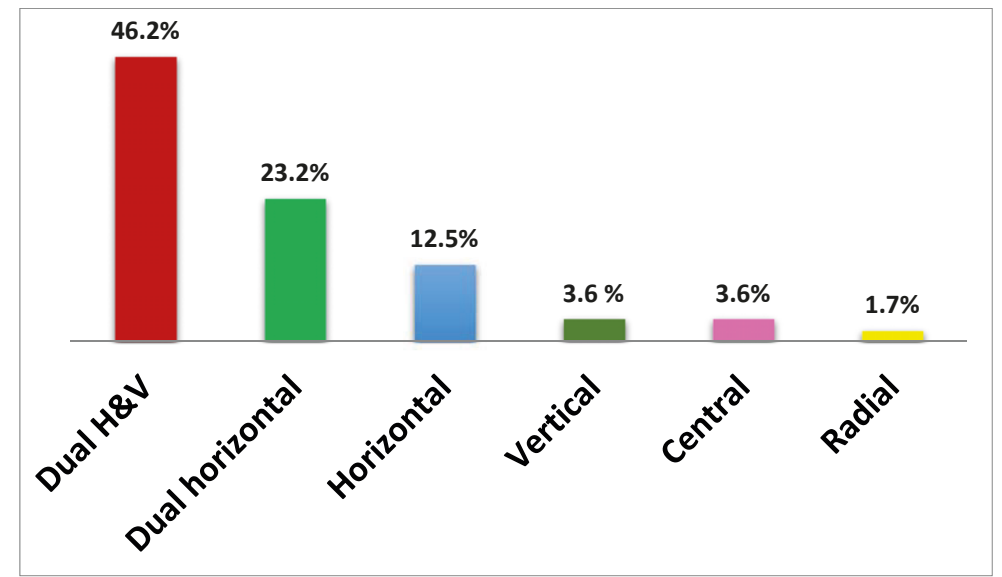

Figure 21. Directionality percentages

Adhesive bonding process: aluminium plates.

Franco González, A.

Graphical abstract.

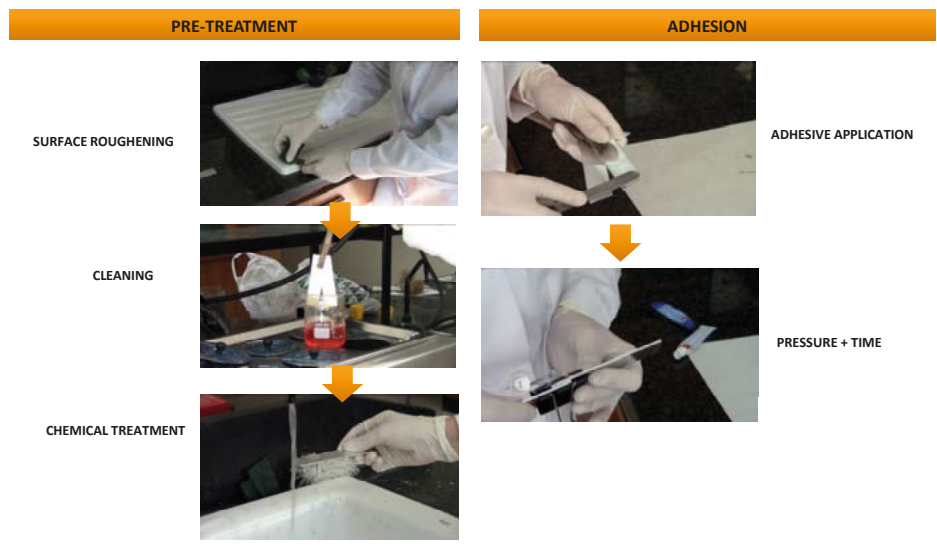

New generation epoxy adhesives: Effect of overlap

length on shearing strength of single-overlap

aluminum 7075 joins

Surface preparation
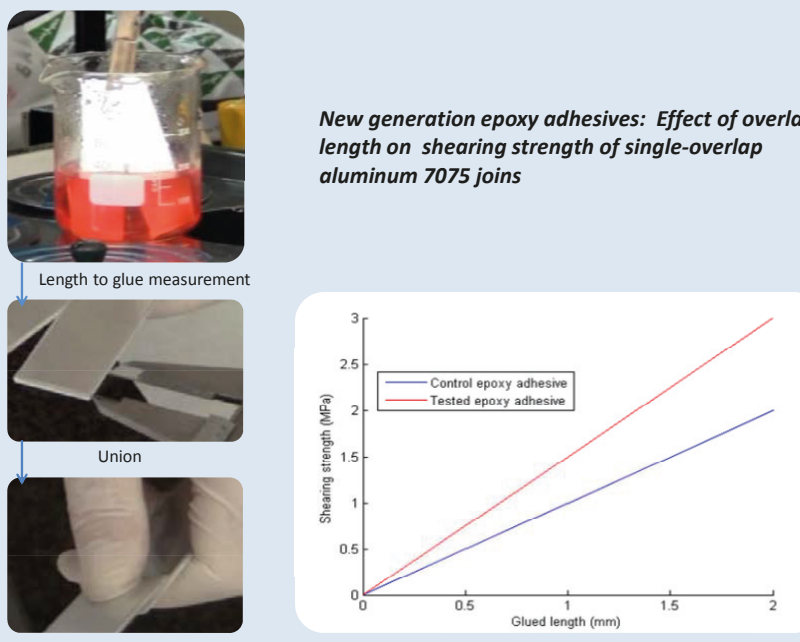

Figures 22A -22B. Vertical paths 
Visual centrality, a traditional marker of relevance, is not always well-targeted by students, which may generate spurious spatial saliency. For example, of starting point achronies (e.g. the untreated aluminum plates in Figure 6A) or of recurrent intermediate steps (e.g. the water rinses in Figure 13), placed right in the middle of the composition without actually deserving such prominence. See, in contrast, the more justifiable centre-stage position of the finished product (i.e. the glued pieces), which is the practice's goal, in Figure 23.

\section{Chemistry practice of aluminum and adhesive joints}

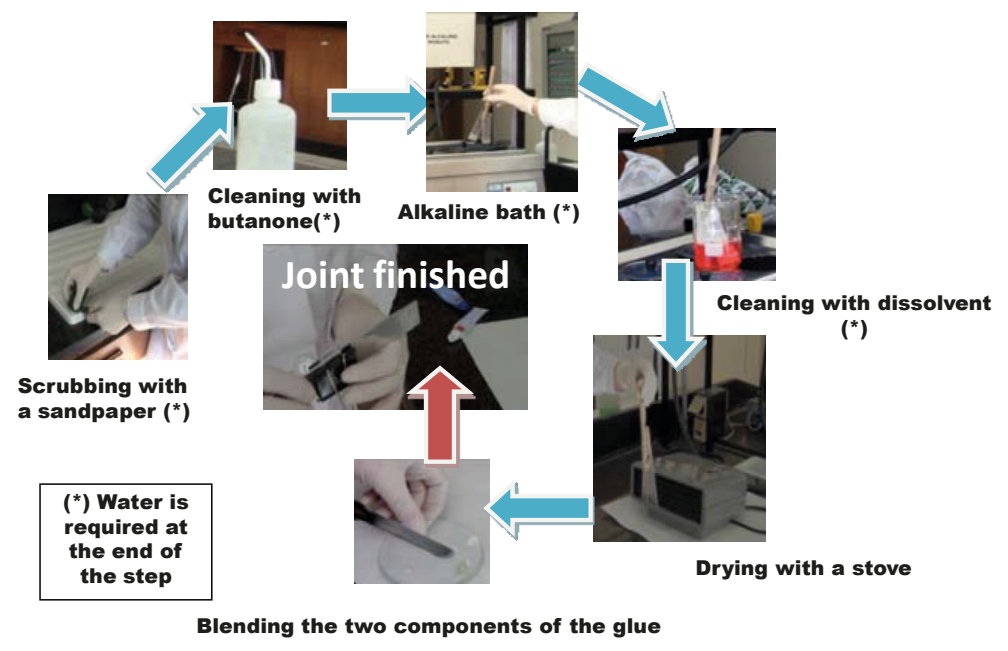

Figure 23. Justifiable centrality

Last but not least in this brief account of GA subjectivity, students are not aware of the pragmatic implications of their register shifts. The phenomenon of register inadequacy in academic discourse, already noticed by Engberg and Maier (forthcoming) in the filmed representation of researchers in video articles, seems to be fostered by the affordances of the new technologies and is not as prevalent in writing. Five samples in my corpus contain such shifts, which range from the verbal interjections "Good job!" and "Done!" at the end of the narrative, to direct informal appeals to the reader, of the type "If you haven't understood the process yet, here it is a graph to understand it", or the typographically emphasized (in upper case and bolds) "The graph is in the next page". Text icons (e.g. a scroll and a mock typed sheet with the header "Instructions") may appear framing interjections and the former messages. On the other hand, inadequacy may also loom as expert discourse, in the form of footnotes (see Figure 23), expected in longer written pieces and too 'academic' for the genre under scrutiny, extremely abridged. 


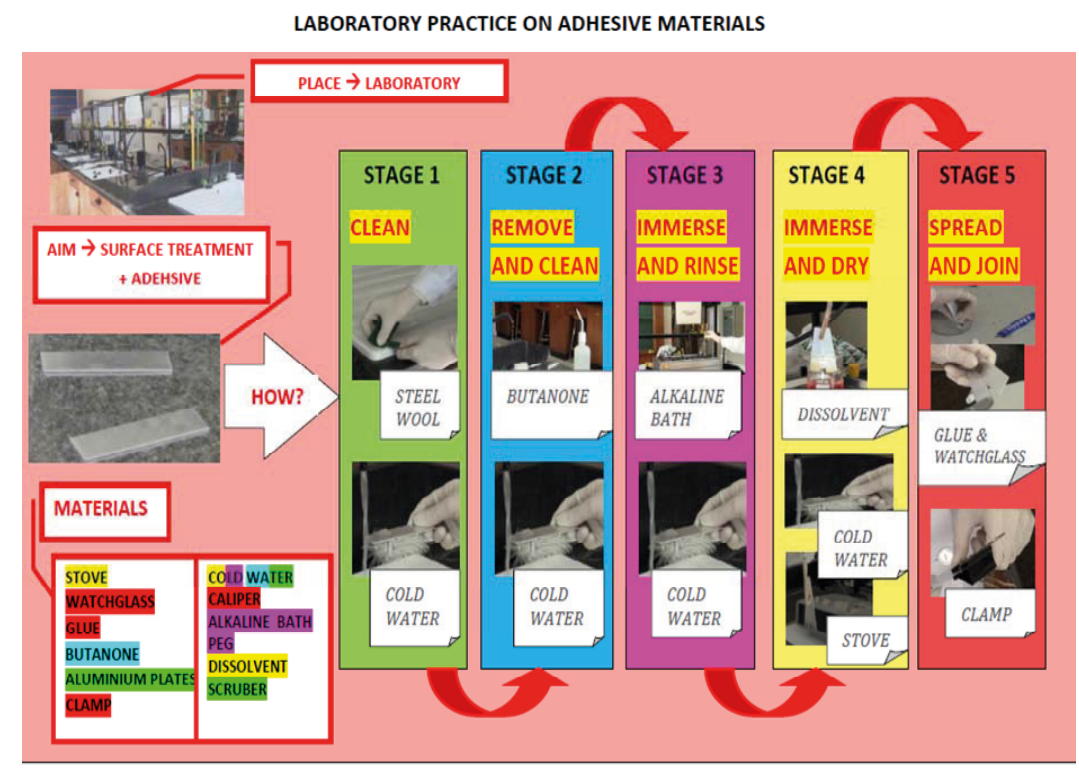

Figure 24. Colour saturation and label overload

From the data scrutinised in this last subsection of the study, we may infer that most students are inclined to laying out narrative stages and steps along a combination of the vertical and horizontal axes, or horizontally in both directions (left-to-right and right-to-left), while other directional choices, such as vertical, central or radial reading paths, remain virtually untapped and the narrative emphasis they place on certain narrative episodes or agents is not always accurate. In like manner, the pragmatic and semantic repercussions of register shifts and stylised embellishments also affect the clarity and tone of the message. It could be said, therefore, that creativity 'takes its toll' on the text's clarity and recapitulative purpose

\section{Closing reflections for teaching GAs in higher education contexts}

All in all, findings reveal that students' GA designs are in the main conventional as to the medium (i.e. computer software) and representation chosen (i.e. a mixture of realistic, schematic and metaphorical depictions but for the greatest part realistic and linear), and in accordance with the rendering expectations raised by the type of text (i.e. a chronologically sequenced narrative), albeit quite versatile with respect to the strategies deployed to transmit specific meanings, such as the use of visual tropes (e.g. metonymic icons) to denote minor steps in the procedure described. Stylisation is moderate in the global layout, but there is a great deal of subjectivity in the representation and arrangement of its integrating elements, and neither the use of visual metadiscourse nor the addressee's disciplinary knowledge can totally bridge comprehension gaps .

With this experimental small-scale study I have attempted to draw attention to the convenience of including graphicacy and GA design in ESP and EMI content curricula. The pedagogical potential of the genre is undeniably broad: it not only foregrounds the ever-growing promotionalism that has colonised the dissemination of science and technology and the changes in the modern researcher's role, but also lends itself to the practice of transversal competences and skills (e.g. of critical and lateral thinking, IT prowess and intercultural and audience awareness) while learning technical or scientific disciplinary contents, acquiring a transductional repertoire (visual and/or multimodal), and reflecting on the possibilities granted by affordances, communicative situations, disciplines and cultures.

Interestingly, the link between critical and creative/divergent thinking in educational models has been largely emphasised by scholars: a threshold level of analytical ability is needed to recog- 
nize challenges and evaluate the feasibility, applicability and efficacy of creative solutions (Renzulli 1986). In other words, creativity cannot exist without the active intervention of the 'triarchic mind' (Sternberg 1988), formed by the analytical, synthetic and practical processing elements of intelligence that enable us to obtain information, make decisions and adapt to the world. And originality and imagination, in turn, are traits of critical thinking (Leicester 2010, Moore 2011), as it involves envisaging alternatives and imagining or predicting what situations might be like. All of these aspects are exercised in the course of GA design, which could be integrated as one more soft skill aimed at helping science and technology students 'read/sound more professional'.

\begin{tabular}{|c|c|}
\hline ITEM & MEANING \\
\hline FRAMES* & $\begin{array}{l}\text { Move/stage/step boundary } \\
\text { Temporal sequence or time lapse if } \\
\text { consecutive }\end{array}$ \\
\hline $\begin{array}{l}\text { VECTORS* } \\
\text { (E.G. ARROWS, LINES, MATHEMATICAL SIGNS, } \\
\text { CAPTIONS, NUMBERS) }\end{array}$ & $\begin{array}{l}\text { Reading path, action/event clustering } \\
\text { (temporal, spatial, causal) } \\
\text { Addition and result (arithmetical signs) }\end{array}$ \\
\hline OBJECT ICONS & Instrumentality, method \\
\hline TICKS AND CROSSES & Pros \& cons, right \& wrong \\
\hline TYPOGRAPHY & $\begin{array}{l}\text { Importance, emphasis, distinctiveness } \\
\text { (classification) }\end{array}$ \\
\hline HAND PERFORMING ACTION & Impersonality, passive voice \\
\hline POTENT CULTURAL SYMBOLOGY* & $\begin{array}{l}\text { Taken-for-granted or well-known } \\
\text { information, inferable property/action }\end{array}$ \\
\hline REGISTER SHIFTS & $\begin{array}{l}\text { Change in interpersonal relationship with } \\
\text { audience }\end{array}$ \\
\hline
\end{tabular}

Table 2. Inventory of semiotic shortcuts I: Items

\begin{tabular}{l|l|}
\multicolumn{1}{|c|}{ COMPOSITION STRATEGY I } & \multicolumn{1}{c}{ MEANING } \\
\hline FROZEN MOMENT/STILL PICTURE & In medias res narrative \\
\hline ANIMATION & Vividness \\
\hline $\begin{array}{l}\text { FOCUS*, FOREGROUNDING* AND } \\
\text { CENTRALITY }\end{array}$ & Saliency, importance, emphasis \\
\hline MARGINALITY & Peripheral information, secondary role \\
\hline EMBEDDING & Subsumed item, inclusion \\
\hline OVERLAPPING* & Simultaneity, superiority \\
\hline INTERSECTION & Commonality \\
\hline PHYSICAL SIMILARITY & Functional equivalence \\
\hline $\begin{array}{l}\text { COLOUR* / TONE* } \\
\text { (CHROMATIC HARMONY vs. DISSONANCE \& } \\
\text { SATURATION) }\end{array}$ & $\begin{array}{l}\text { Importance, emphasis, classification, } \\
\text { cohesion/unity }\end{array}$ \\
\hline SIZE* & Importance, emphasis \\
\hline
\end{tabular}

Table 3. Inventory of semiotic shortcuts II: Composition strategies 


\begin{tabular}{|l|l|}
\multicolumn{1}{|c|}{ COMPOSITION STRATEGY II } & MEANING \\
\hline SCHEMATISATION & Emphasis on essential features \\
\hline STYLISATION/EMBELLISHMENT & Authorial presence \\
\hline METAPHORISATION & Authorial stance \\
\hline DIRECTIONALITY & $\begin{array}{l}\text { Reading path \& information flow } \\
L \rightarrow R \text { (given } \rightarrow \text { new information) } \\
R \rightarrow L \text { (new } \rightarrow \text { given) } \\
T \rightarrow B \text { (given } \rightarrow \text { new/ideal } \rightarrow \text { real) } \\
B \rightarrow T \text { (new } \rightarrow \text { given/real } \rightarrow \text { ideal) }\end{array}$ \\
\hline & \\
\hline & \\
\hline
\end{tabular}

Table 4. Inventory of semiotic shortcuts III: Composition strategies

In this vein, if the bi- and multi-modal representation of knowledge should become part and parcel of scientific education and future scientists are to take up the challenges posed by GAs (i.e. incompleteness, instability, trivialization and subjectivity) in the selection of information and genre moves, their composition and their interpretation, and genre users may agree on and defy genre conventions (Hyland 2004), as teachers of academic and professional communication we should lay the foundations for stable cross-disciplinary and cross-cultural repertoires. A productive point of departure could be Kress and van Leeuwen's (1996) visual grammar (whose elements are marked with an asterisk in Tables 2 and 3), which could be expanded with the contributions (i.e. the 'semiotic shortcuts') of professionals and students. As my corpus samples and their reception have suggested, students may by themselves discover Kress and van Leeuwen's grammar principles and go beyond them with self-devised transductions, but disciplinary expertise and the use of vectors do not secure their comprehension and alternative semiotic strategies should be concerted. An exciting new avenue for research could be the exploration of visual synonymy and the visual encoding of modalised and epistemic meanings, which are discouraged by high-impact journals such as Cell. The interactive university classroom might become a fertile site for collective endeavours in search of valid transductional signifiers.

\section{Appendix}

\section{Interview questions}

1) What approximate percentage of graphic information do students handle in the subject matter you teach? With what specific informative function? Illustrative of the verbal text? Complementary to it? As an independent message?

2) What types of tasks involving graphics/visuals do you assign to your students?

\section{References}

Balchin, William G.V./Coleman, Alice M. 1966: Graphicacy Should Be the Fourth Ace in the Pack. The Cartographer 3(1), 23-28. (Original work published in The Times Educational Supplement, 5 November 1965). 
Bateman, John A. 2011: The Decomposability of Semiotic Modes. In O’Halloran, Kay L./Smith, Bradley A. (eds.), Multimodal Studies: Multiple Approaches and Domains. London: Routledge, 17-38.

Blommaert, Jan 2005: Discourse. Cambridge: Cambridge University Press.

Bhatia, Vijay K. 2004: Worlds of Written Discourse. A Genre-Based View. London: Continuum.

Bhatia, Vijay K. 2014: Managing Interdiscursive Space in Professional Communication.

In Evangelisti Allori, Paola/Bateman, John/Bhatia, Vijay K. (eds.), Evolution in Genre: Emergence, Variation, Multimodality. Bern: Peter Lang, 95-113.

Black, Beth (ed.) 2012: An A to Z of Critical Thinking. London/New York: Continuum.

Cambrosio, Alberto/Jacobi, Daniel/Keating, Peter 2006: Arguing with Images: Pauling's Theory of Antibody Formation. In Pauwels, Luc (ed.), Visual Cultures of Science. Rethinking Representational Practices in Knowledge Building and Science Communication. Hanover, NH: Dartmouth College Press, 153-194.

Dondis, Donis A. 1973: A Primer of Visual Literacy. Cambridge, MA: MIT Press.

Dwyer, Francis M. 1972: A Guide for Improving Visualized Instruction. State College, PA: Learning Services.

Engberg, Jan/Maier, Carmen D. Forthcoming: Researchers' Move from Page to Screen: Addressing the Effects of the Video Article Format Upon Academic User Engagement and Knowledge Building Processes. In Sancho Guinda, C. (ed.), Engagement in Professional Genres: Deference and Disclosure. Amsterdam: John Benjamins.

European Parliament and the Council 2006: Recommendation of the European Parliament and of the Council of 18 December 2006 on Key Competences for Lifelong Learning (2006/962/EC) [online]. http://eur-lex.europa.eu/legal-content/EN/TXTn/?uri=celex:32006H0962

Fredlund, Tobias/Linder, Cedric/Airey, John 2014: Reverse Rankshift: an Appreciation of the Disciplinary Affordances of Representations. Presentation delivered at the $5^{\text {th }}$ International $360^{\circ}$ Conference: Encompassing the Multimodality of Knowledge. Department of Business Communication, School of Business and Social Sciences, Aarhus University (Denmark), May 8-10, 2014.

Gross, Alan G./Harmon, Joseph E./Reidy, Michael S. 2009: Communicating Science. The Scientific Article from the $17^{\text {th }}$ Century to the Present. West Lafayette, IN: Parlor Press.

Gross, Alan G./Chesley, Paula 2012: Hedging, Stance and Voice in Medical Research Articles. In Hyland, Ken/Sancho Guinda, Carmen (eds.), Stance and Voice in Written Academic Genres. Basingstoke, UK: Palgrave Macmillan, 85100.

Hoffmann, Christian R. 2010: Introduction: Narrative Revisited. Telling a Story in the Age of New Media. In Hoffmann, Christian R. (ed.), Narrative Revisited. Telling a Story in the Age of New Media. Amsterdam: John Benjamins, 1-18.

Hyland, Ken 2004: Disciplinary Discourses Social Interactions in Academic Writing. Ann Arbor, MI: The University of Michigan Press.

Hyland, Ken 2005: Metadiscourse. Exploring Interaction in Writing. London: Continuum.

Kress, Gunther 2010: Multimodality: A Social Semiotic Approach to Contemporary Communication. New York: Routledge.

Kress, Gunther/van Leeuwen, Theo 1996: Reading Images. The Grammar of Visual Design. London: Routledge.

Kress, Gunther/van Leeuwen, Theo 2001: Multimodal Discourse. The Modes and Media of Contemporary Communication. London: Bloomsbury.

Latour, Bruno 1990: Drawing Things Together. In Lynch, Michael L./Woolgar, Steve (eds.), Representation in Scientific Practice. Cambridge, MA: MIT Press, 19-68.

Latour, Bruno/Woolgar, Steve 1979: Laboratory Life: The Social Construction of Scientific Facts. London: Sage.

Leicester, Mal 2010: Teaching Critical Thinking Skills. London: Continuum.

Lynch, Michael 2006: The production of Scientific Images: Vision and Re-Vision in the History, Philosophy, and Sociology of Science. In Pauwels, Luc (ed.), Visual Cultures of Science. Rethinking Representational Practices in Knowledge Building and Science Communication. Hanover, NH: Dartmouth College Press, 26-40.

Machin, David 2007: Introduction to Multimodal Analysis. New York: Hodder Arnold.

Maier, Carmen D./Engberg, Jan 2013: Tendencies in the Multimodal Evolution of Narrator's Types and Roles in Research Genres. In Gotti, Maurizio/Sancho Guinda, Carmen (eds.), Narratives in Academic and Professional Genres. Bern: Peter Lang, 149-173.

Messaris, Paul 1994: Visual Literacy: Image, Mind and Reality. Boulder, CO: Westview Press.

Messaris, Paul 1998: Visual Aspects of Media Literacy. In Journal of Communication 48(I) (Winter), 70-80.

Moore, Timothy J. 2011: Critical Thinking and Language. The Challenge of Generic Skills and Disciplinary Discourse. London/New York: Continuum. 
Myers, Greg 2003: Words, Pictures and Facts in Academic Discourse. In Ibérica 6, 3-13.

Pauwels, Luc 2006a: A Theoretical Framework for Assessing Visual Representational Practices in Knowledge Building and Science Communication. In Pauwels, Luc (ed.), Visual Cultures of Science. Rethinking Representational Practices in Knowledge Building and Science Communication. Hanover, NH: Dartmouth College Press, 1-25.

Pauwels, Luc 2006b: Representing Moving Cultures: Expression, Multivocality and Reflexivity in Anthropological and Sociological Filmmaking. In Pauwels, Luc (ed.), Visual Cultures of Science. Rethinking Representational Practices in Knowledge Building and Science Communication. Hanover, NH: Dartmouth College Press, 120-152.

Pérez-Llantada, Carmen 2012: Scientific Discourse and the Rhetoric of Globalisation. The Impact of Culture and Language. London: Bloomsbury.

Poracsky, Joseph/Young, Emily/Patton, Judy P. 1999: The Emergence of Graphicacy. In The Journal of General Education 48(2), 103-110.

Prensky, Marc 2011: Enseñar a Nativos Digitales. Una Propuesta Pedagógica para la Sociedad del Conocimiento. (Title of original work: Teaching Digital Natives. Partnering for Real Learning) Trans. Elena Alemany. Madrid: Ediciones SM.

Renzulli, Joseph S. 1986: The Three-ring Conception of Giftedness. A Developmental Model for Creative Productivity. In Sternberg, Robert J./Davidson Janet E. (eds.), Conceptions of Giftedness. New York: Cambridge University Press, 53-92.

Ryan, Marie-Laure (ed.) 2004: Still Pictures. In Ryan, Marie-Laure (ed.), Narrative across Media. The Languages of Storytelling. Lincoln/London: University of Nebraska Press, 139-144.

Sales, Hazel E. 2006: Professional Communication in Engineering. Basingstoke, UK: Palgrave Macmillan.

Sancho Guinda, Carmen 2011: Integrating Approaches to Visual Data Commentary. An Exploratory Case Study. In Bhatia, Vijay K./Sánchez Hernández, Purificación/Pérez- Paredes, Pascual (eds.), Researching Specialized Languages. Amsterdam: John Benjamins, 115-135.

Sancho Guinda, Carmen 2012a: Proximal Positioning in Students' Graph Commentaries. In Hyland, Ken/Sancho Guinda, Carmen (eds.), Stance and Voice in Written Academic Genres. Basingstoke, UK: Palgrave Macmillan, 166-183.

Sancho Guinda, Carmen 2012b: Variation in Students' Accounts of Graphic Data: Context and Cotext Factors in a Polytechnic Setting. In Berkenkotter, Carol/Bhatia, Vijay K./Gotti, Maurizio (eds.), Insights into Academic Genres. Bern: Peter Lang, 355-376.

Sancho Guinda, Carmen 2014a: Abridged Abstracts: Rushing the Research Race? In Revista Canaria de Estudios Ingleses 69, 15-33.

Sancho Guinda, Carmen 2014b: Alignment Strategies and Genre Variation in Students' Graph Commentaries. In Evangelisti Allori, Paola/Bateman, John/Bhatia, Vijay K. (eds.), Evolution in Genre: Emergence, Variation, Multimodality. Bern: Peter Lang, 167-190.

Sancho Guinda, Carmen 2015: Genres on the Move: Currency and Erosion of the Genre Moves Construct. In Journal of English for Academic Purposes 19, 73-87.

Swales, John M. 2004: Research Genres. Explorations and Applications. Cambridge: Cambridge University Press.

Swales, J.M. 2014: Afterword. In Bondi, Marina/Lorés Sanz, Rosa (eds.), Abstracts in Academic Discourse. Bern: Peter Lang, 319-323.

Swales, John M./Feak, Christine B. 1994: Academic Writing for Graduate Students. A Course for Nonnative Speakers of English. Ann Arbor: The University of Michigan Press.

Thornbury, Scott 2006: An A-Z of ELT. A Dictionary of Terms and Concepts Used in Language Teaching. Oxford: Macmillan.

Trumbo, Jean 2006: Making Science Visible: Visual Literacy in Science Communication.

In Pauwels, Luc (ed.), Visual Cultures of Science. Rethinking Representational Practices in Knowledge Building and Science Communication. Hanover, NH: Dartmouth College Press, 266-283.

Tufte, Edward 1983: The Visual Display of Quantitative Information. Cheshire, CT: Graphics Press.

Wenger, Etienne 1998: Communities of Practice. Learning, Meaning and Identity. Cambridge: Cambridge University Press. 